ISSN: 0514-7336 — ISSN electrónico: 2386-3943

DOI: https://doi.org/10.14201/zephyrus2020855378

\title{
DOS BOCADOS DE BRONCE HISPANO-FENICIOS EN EL METROPOLITAN MUSEUM OF ART (NEW YORK): EN TORNO A LA FUNCIONALIDAD E ICONOGRAFÍA DEL BRONCE CARRIAZO
}

\section{Two West Phoenician bronze horse bits in the Metropolitan Museum of Art (New York): On the function and iconography of the so-called Bronze Carriazo}

\author{
F. Javier JimÉnez Ávila* y Alfredo Mederos Martín** \\ * Consejería de Cultura y Deportes. Junta de Extremadura. Paseo de Roma. 06800 Mérida. Correo-e: jjimavila@ \\ hotmail.com. ID ORCID: https://orcid.org//0000-0002-3431-0395 \\ ** Dpto. de Prehistoria y Arqueología. Facultad de Filosofía y Letras-UAM. Campus de Cantoblanco. 28049 Madrid. \\ Correo-e: alfredo.mederos@uam.es.ID ORCID: https://orcid.org/0000-0002-0036-7940
}

Recepción: 03/02/2020; Revisión: 28/03/2020; Aceptación: 18/04/2020

Resumen: En el Metropolitan Museum of Art, New York, se conservan dos placas de bronce que reproducen la iconografía del célebre Bronce Carriazo. Se consideran camas laterales de un bocado de caballo elaborado por un taller fenicio occidental en torno al s. vir a. C., y presentan algunas diferencias iconográficas y, sobre todo, técnicas, con la conocida pieza sevillana. Los bocados representan a la diosa qudšu 'aštart, una divinidad alada guerrera vinculada a la realeza fenicia. Las dos cabezas de ánades a ambos extremos parecen formar la proa y la popa de una barca solar, con el sol simbolizado en una roseta central, pues el barco solar realizaba el viaje al más allá en el extremo Occidente, navegando por un cielo de agua. Estas producciones de bronces hispano-fenicios, inspiradas en los repertorios orientales, reflejan la asunción por las aristocracias orientalizantes de la Península Ibérica de una ideología y simbología mítica y religiosa de raigambre oriental en el Hierro Antiguo.

Palabras clave: bronces; atalaje ecuestre; Orientalizante; Península Ibérica; religión.

Aвstract: The Metropolitan Museum of Art, in New York, exhibits two bronze plaques which reproduce the iconography of the famous Spanish item known as 'Bronce Carriazo'. They are considered as lateral cheeks of a horse bridle bit cast by a West Phoenician workshop around the 7th century BC. They present some iconographic and, above all, technical differences with the Sevillian piece. These horse harness pieces represent the goddess qudšn 'aštart, a winged warrior divinity linked to the Phoenician royalty. The two heads of birds at the upper edges seem to configure the bow and the stern of a solar boat (the sun itself is symbolized in a central rosette). It would be the solar ship that sails through a water sky, depicting the trip to the otherworld in the extreme West. These Hispanic-Phoenician bronzes are inspired by the oriental repertoires and they reflect the assumption of a mythical and religious ideology, strongly rooted in Orient, by the western Iberian aristocracies throughout the Early Iron Age.

Key words: Bronzes; horse harness; Orientalising Period; Iberian Peninsula; religion.

Ediciones Universidad de Salamanca / @@@

Zephyrus, LXXXV, enero-junio 2020, 53-78 


\section{Introducción ${ }^{1}$}

Desde 1999 se conservan en el Museo Metropolitano de Arte de New York -en adelante MMA- dos objetos de bronce que se asemejan en casi todo al conocido Bronce Carriazo, pieza emblemática de la protohistoria meridional que actualmente se custodia en el Museo Arqueológico de Sevilla ${ }^{2}$-en adelante MASE-. Fue el profesor Maluquer de Motes, fundador de Zephyrus, quien eligió esta misma revista para presentar tan representativa obra a la comunidad científica en los años cincuenta del siglo pasado (Maluquer de Motes, 1957), y desde entonces ha sido objeto de numerosos estudios y menciones que la han convertido en un referente imprescindible de la investigación sobre iconografía fenicia y orientalizante en la Península Ibérica (Blanco Freijeiro, 1960; García y Bellido, 1969; Carriazo, 1973; 1974; Jiménez Ávila, 2002; 2015; Marín y Ferrer, 2011). Por eso, nos parecía este un medio ideal para abordar el estudio de detalle de estos dos testimonios tan similares al célebre bronce sevillano.

Se trata de dos placas caladas con decoración figurativa, identificables como camas laterales de bocados de caballo ${ }^{3}$. En los registros del museo neoyorquino consta su procedencia de la Península Ibérica y su recorrido anterior por varios anticuarios, primero por el establecimiento del comerciante londinense Kenneth J. Hewett, que fue quien las adquirió en primera instancia, y después por el de Robert E. Hecht, anticuario americano con sede en París especializado en el mercado italiano ${ }^{4}$-sobre todo en piezas etruscas, itálicas y griegas procedentes de

\footnotetext{
1 Queremos manifestar nuestro agradecimiento al personal del Metropolitan Museum of Art que nos atendió durante y después de nuestro trabajo de campo: J. Aruz, M. J. Hatz, J.-F. de Laperouse y, muy especialmente, a A. E. Dunn-Vaturi. Igualmente, a J. M. Jerez por la rapidez y la calidad de los dibujos de las piezas, a J. C. Conde por los retoques fotográficos y al Prof. M. Almagro-Gorbea por sus siempre aleccionadoras indicaciones.

2 Inventario Do-6902; ficha museográfica disponible en www.ceres.mcu.es, con más bibliografía.

3 Portan los n. ${ }^{\text {os }}$ inv. 1999.80 a y 1999.80 b.

4 Inventario Do-6902; ficha museográfica disponible en www.ceres.mcu.es, con más bibliografía.
}

Etruria-, quien las adquirió a Hewett ya en los años sesenta del siglo pasado.

Exhibidas en las Salas de Antigüedades Orientales junto al conocido jarro de Las Fraguas -también de procedencia hispánica-, fueron reconocidas en noviembre de 2000, durante su asistencia al seminario Italy and Cyprus in Antiquity 1500-450 BC, por M. Almagro-Gorbea y A. Mederos quienes, rápidamente, informaron de su existencia a varios investigadores que estudiaban temáticas relacionadas con ellas y que las refieren en varios trabajos de esa época, aunque sin aportar material gráfico alguno. Así, en la publicación de la tesis sobre Tartessos de M. Torres (2002: 266), en la de J. Jiménez Ávila (2002: 227, n. 78; 516) sobre la toréutica orientalizante en la Península Ibérica, donde son mencionadas en un apéndice fuera de catálogo, o en el estudio sobre el atalaje ecuestre de Cancho Roano de M. Blech (2003: 168).

Posteriormente fueron tratadas en un trabajo de R. Corzo (2007), quien por primera vez aporta material gráfico - unas fotos de las piezas en su vitrina$y$, a partir de una comparación estilística, considera que son reproducciones modernas. También con fotografías de vitrina debidas a R. Pliego son mencionadas en el estudio sobre el Bronce Carriazo de $\mathrm{M}$. C. Marín Ceballos y E. Ferrer (2011: 618, 629, 636, figs. 4 y 5), que es la aproximación monográfica más reciente para este objeto, donde plantean para ellas un posible origen oriental. Finalmente, son referidas en un trabajo de conjunto sobre la broncística fenicia occidental, de nuevo como paralelos del Bronce Carriazo, incluyendo una fotografía del propio MMA que permite la comparación directa entre ambas piezas (Jiménez Ávila, 2015: 433, fig. 40).

Por nuestra parte, en 2003 pudimos acceder directamente a estas dos placas, examinarlas y dibujarlas en las instalaciones del Metropolitan, resultando de este trabajo los datos que aquí aportamos y las conclusiones que sumamos a los distintos debates que de ellas han surgido.

\section{Aspectos formales y funcionales}

La placa 1999.80a (Fig. 1, n. ${ }^{\circ} 1$ y Fig. 2) presenta unas dimensiones de $14,6 \mathrm{~cm}$ de longitud $\mathrm{x} 10 \mathrm{de}$ 
altura máxima x 3,9 de ancho, siendo el grosor medio de la pieza de unos $0,5 \mathrm{~cm}$, si bien se trata esta de una magnitud variable, como corresponde a un objeto de morfología compleja. Su peso es de $349 \mathrm{~g}$.

La placa 1999.80b (Fig. 1, n. ${ }^{\circ} 2$ y Fig. 3), muy similar a la anterior, mide $15,6 \mathrm{~cm}$ de longitud, ya que conserva los picos de las aves que forman sus extremos en mejor estado; su altura es de $9,8 \mathrm{~cm}$ y su anchura máxima de $2,5 \mathrm{~cm}$, siendo el grosor medio algo mayor que el de su pareja. Su peso es de $340 \mathrm{~g}$.

El motivo representado en ambas es el mismo, con las variaciones propias de un trabajo manual y artesanal, por lo que basta con una única descripción para las dos piezas, señalando las pequeñas diferencias observables entre ellas. Del mismo modo, su extraordinario parecido con el Bronce Carriazo obliga a una continuada referencia comparativa a esta célebre obra.

Presentan una composición simétrica, presidida por el torso de una figura humana femenina que, por extender los brazos hacia arriba, adquiere una estructura en ' $v$ ' o triángulo invertido. De la figura destaca la cara, por su situación central y por estar enmarcada por otros elementos de la composición; es de silueta oval y lados rectos, con dos orejas en las sienes representadas en visión frontal. Las orejas se anteponen al cabello, que es uno de los elementos más reconocibles en ambas figuras, y que reproduce el esquema del típico peinado hathórico, con raya central y dos grandes bucles laterales que caen sobre los hombros, resaltados con múltiples líneas incisas paralelas. Los rasgos faciales representados son unos ojos incisos en forma de almendra -de base recta en el ejemplar b-, una nariz en relieve, desgastada en ambas piezas, y una boca sugerida mediante una estrecha incisión horizontal ligeramente reforzada en el ejemplar b. La figura luce una ceñida prenda de la que se reconocen los bordes en el cuello, marcados por un grueso bocel, y en los brazos, donde se representan las mangas cortas mediante una ligera depresión recta y oblicua a la dirección del miembro. Los brazos, como queda dicho, se elevan formando un ángulo prácticamente recto, empuñando las manos dos objetos triangulares de difícil definición y que, en las interpretaciones del Bronce
Carriazo, se han leído como sistros o como flores de loto. Solo se conserva completo el ejemplar derecho de la pieza b, habiendo perdido los otros tres el tramo superior horizontal que permite entenderlos como los agarraderos superiores de la pieza. Tanto los brazos como los agarres triangulares se trabajan en calado. En la zona equivalente al pecho, en el eje de la composición, ambas figuras ostentan una roseta incisa de 16 pétalos de bordes redondeados. Las diferencias más notables entre ambas figuras, aparte de las ya señaladas concernientes a los rasgos faciales, se refieren a la presencia de una línea oblicua de troqueles circulares - a modo de perlas- y unas incisiones angulares en el cuello de la figura a, entre el óvalo facial y el cuello del vestido, que parecen simular una especie de gargantilla, y que recuerdan lejanamente al collar de flores abiertas y cerradas que porta el Bronce Carriazo. Por abundar en la comparación con esta obra, se puede señalar la ausencia de incisiones triangulares en las frentes que afecta a las piezas del MMA, así como de las bandas laterales situadas bajo las orejas que parecen recoger el cabello en la pieza del MASE y que tampoco aparecen en las de New York; o de los ribetes que subrayan las mangas de los vestidos y las pulseras, que hacen de la diosa del Bronce Carriazo una figura más ornamentada y mejor acabada. Los mangos de los objetos que empuñan los personajes también presentan algunas diferencias, siendo rectos y estrechos en el Bronce Carriazo pero anchos y extrañamente triangulares en los bronces del Metropolitan. Finalmente, desde el punto de vista del modelado, se aprecia un mayor trabajo en la pieza de Sevilla, que presenta una superficie facial algo más modulada en ojos y boca, marcándose en ella más profundamente carrillos y comisuras.

De los laterales del personaje central brotan sendas figuras ornitomorfas tratadas de perfil, generando una composición heráldica y emblemática de gran efectismo y valor estético. Las especies representadas podrían ser anátidas, como denuncian los picos mejor conservados de la placa b, que son los que más se asemejan a los de la pieza sevillana. De los animales se representan las cabezas de perfil y con el pico cerrado; las alas -solo se ve una en cada 


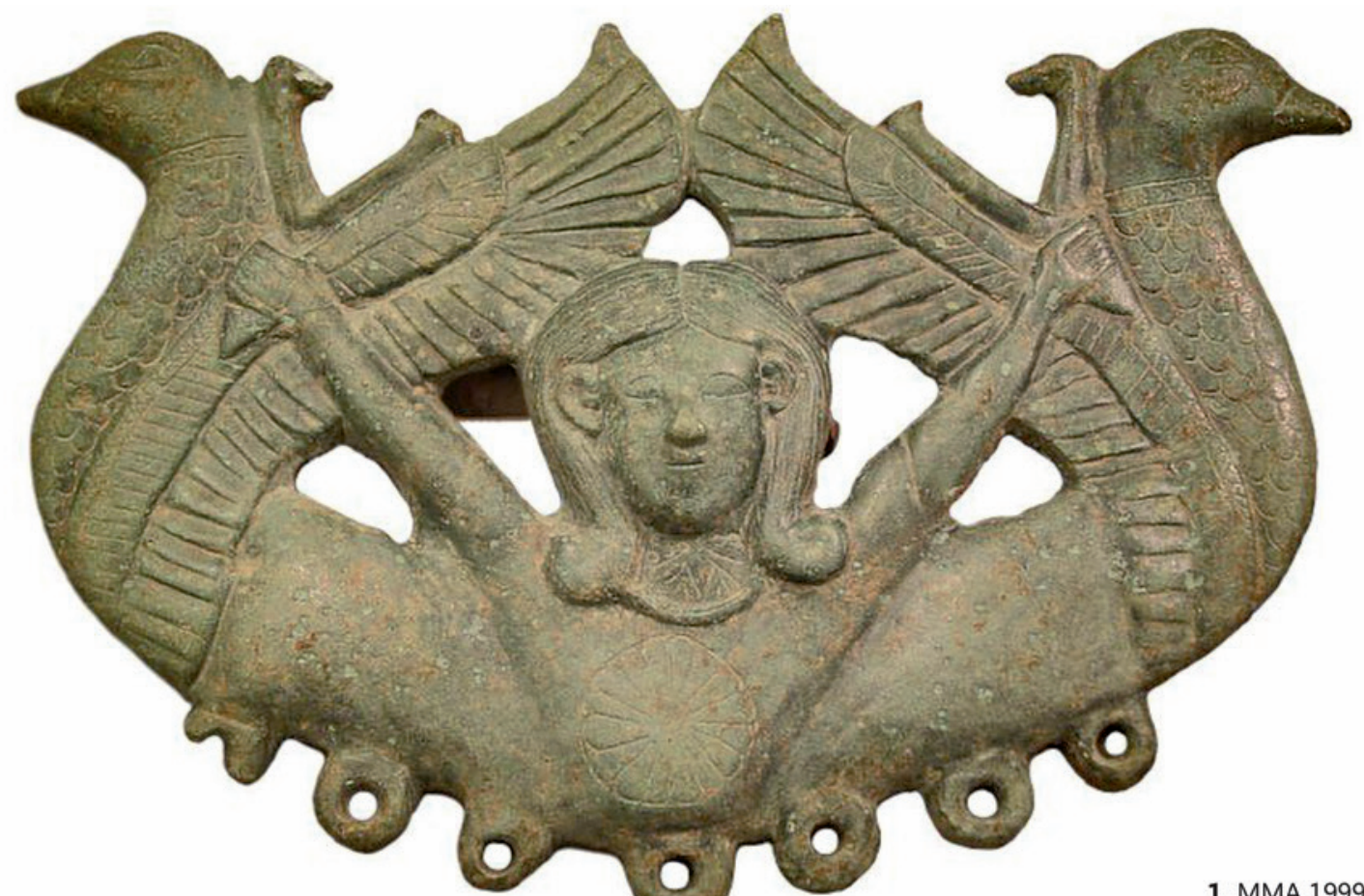

1. MMA 1999.80a

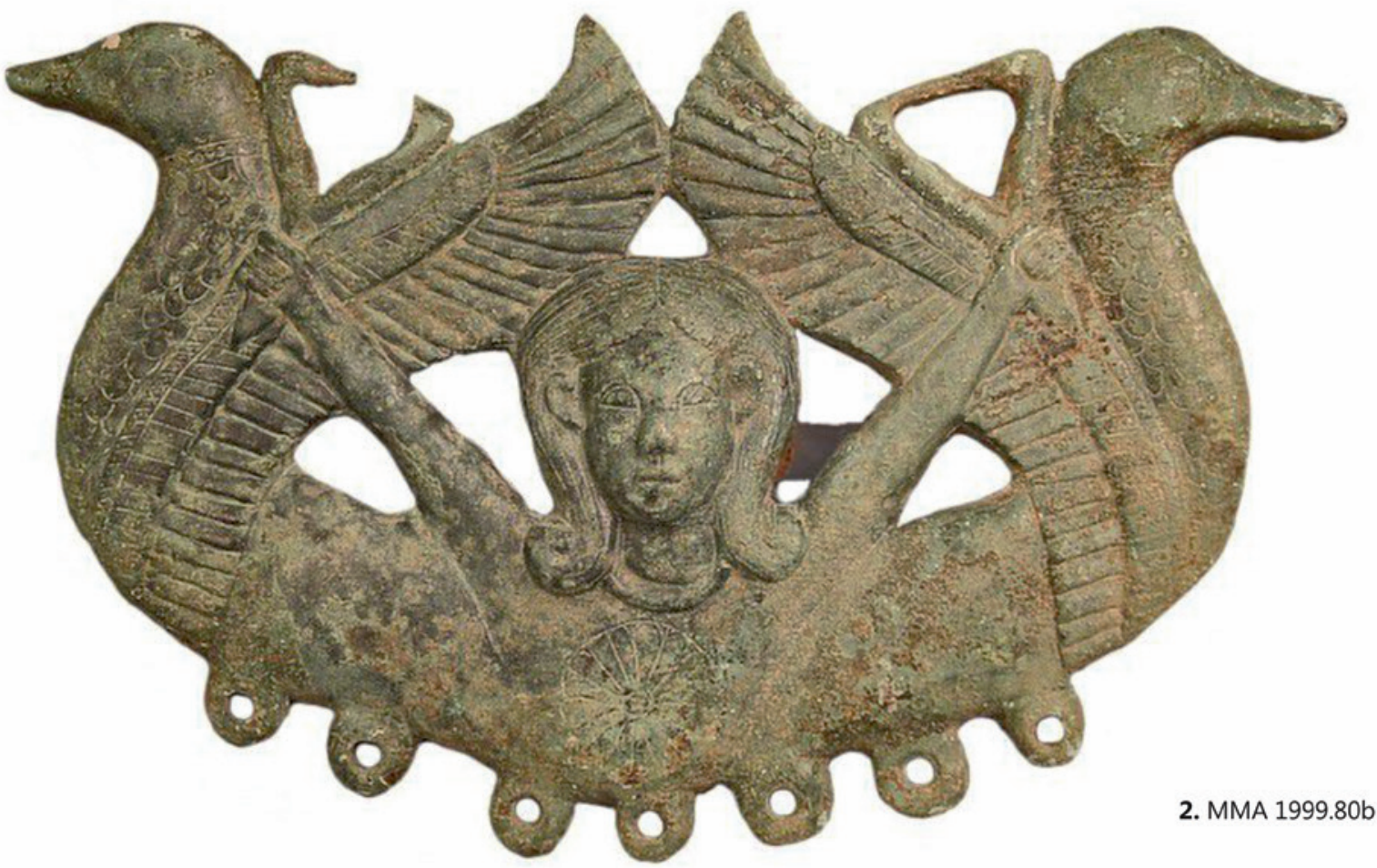

Fig. 1. Par de camas de bronce procedentes de la Peninsula Ibérica conservadas en el Metropolitan Museum of Art, New York, vistas frontales (fotografía J. Jiménez Ávila). 


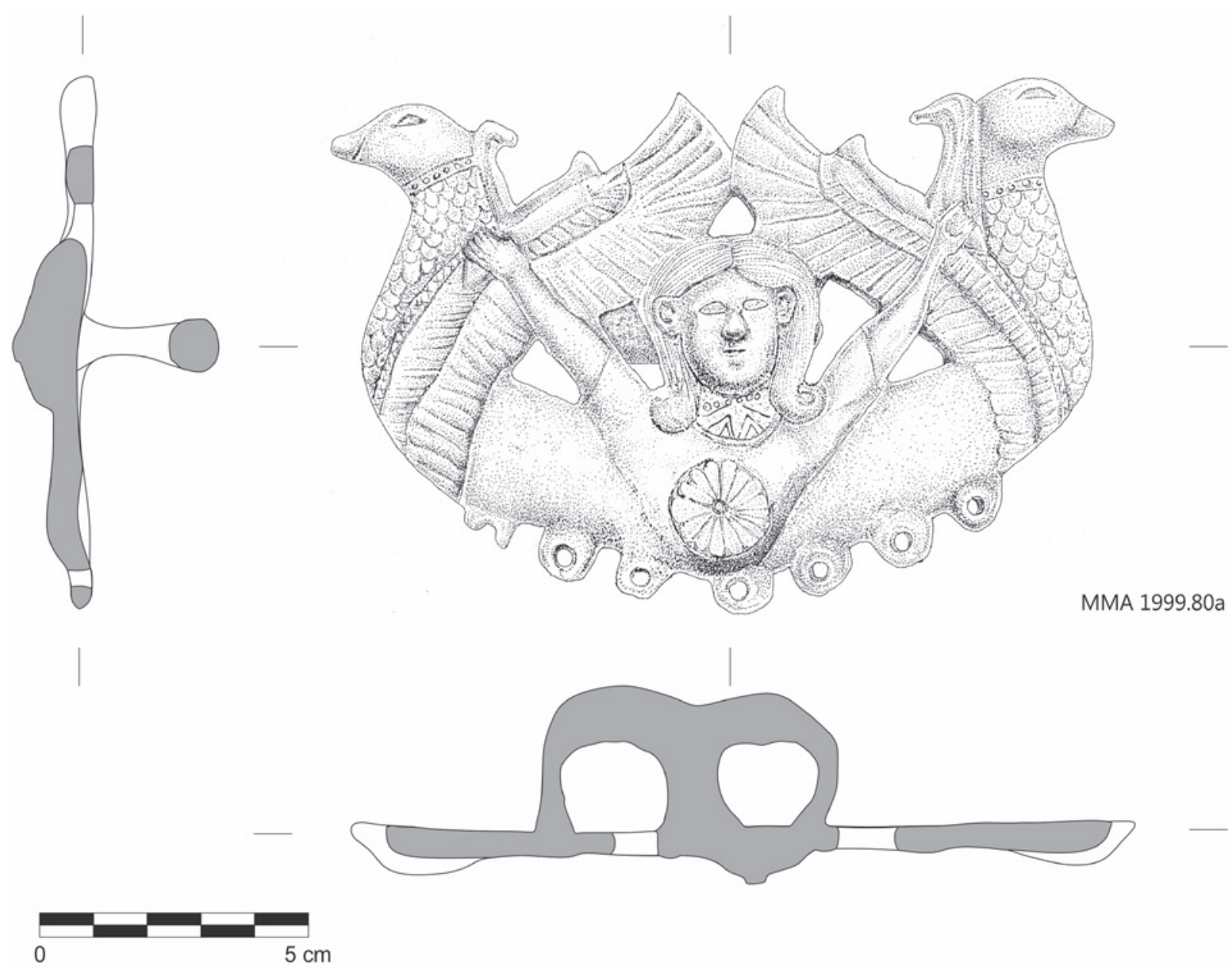

Fig. 2. Dibujo de la placa 1999.80a: vista frontal y secciones (J. Jiménez Ávila-J. M. Jerez).

ave- desplegadas en abanico por detrás de los brazos de la figura central y contactando ligeramente en el eje vertical de la pieza, sobre la cabeza del personaje femenino, dejando un hueco calado triangular sobre el cráneo; los cuellos, largos y sinuosos, y las destacadas pechugas, que se unen a un cuerpo curvado, a modo de bocel, que constituye la base de la pieza y donde las formas naturalistas de animales y humanos se desdibujan para dar paso a las necesidades funcionales del objeto, si bien el aspecto general de la pieza, gracias a esta incurvación inferior, adquiere un marcado aspecto barquiforme. La curvatura inferior de las camas se dota de siete lengüetas perforadas que debieron actuar como argollas para sujetar otros tantos colgantes hoy perdidos 5 .

La silueta de las aves se complementa con un sumario trabajo en relieve que modela sus formas $y$, sobre todo, con una decoración incisa que articula su anatomía y define sus distintas partes. De este modo, las cabezas aparecen lisas, y en ellas se trabajan los ojos, de forma almendrada, a veces con la línea inferior más recta, y de tamaño

5 En alguna ocasión se ha afirmado que sobreviven los alambres que sujetarían estos colgantes (Marín y Ferrer, 2011: 629). Se trata de un error producto del trabajo con fotos de vitrina, ya que lo que se observa en las mismas son las pequeńas alcayatas de alambre que sujetan las piezas al soporte museográfico. 
desproporcionadamente grande, especialmente en el ejemplar a. Se separan del pico por una incisión oblicua y del cuello por un estrecho collarín constituido por dos líneas horizontales y una serie de pequeños troqueles circulares entre ellas. Los cuellos, hasta su juntura con el arranque de las alas, se decoran con series de lengüetas incisas, imitando las plumas, que se disponen al tresbolillo, aunque sin mucha regularidad. Las alas se estructuran en dos partes, con un ancho reborde exterior donde se reproducen las plumas remeras, mediante un trabajo en relieve a base de excisiones rectas en disposición radial que simulan un falso escalonamiento. En el trabajo de estos elementos es donde se evidencian de forma más palpable las diferencias de pericia artesanal con el Bronce Carriazo, ya que el número de estas plumas -que oscila entre 25 y $27-$, la rectitud de las aristas, su tamaño y su ordenación son mucho menos uniformes en estos bronces del MMA, sin que ello quiera decir que las del Bronce Carriazo sean perfectamente regulares. Los alones, que sobresalen en relieve, aparecen también compartimentados y decorados. En ellos se trabaja un ancho reborde paralelo al exterior en el que, de nuevo, se graban mediante trazos rectos una serie de 'plumas' menores de disposición similar a las externas y, como ellas, dispuestas con gran irregularidad. Finalmente, el tramo restante, que hasta las manos de las figuras femeninas forma un estrecho filete, se decora con una sucesión de aspas también incisas,

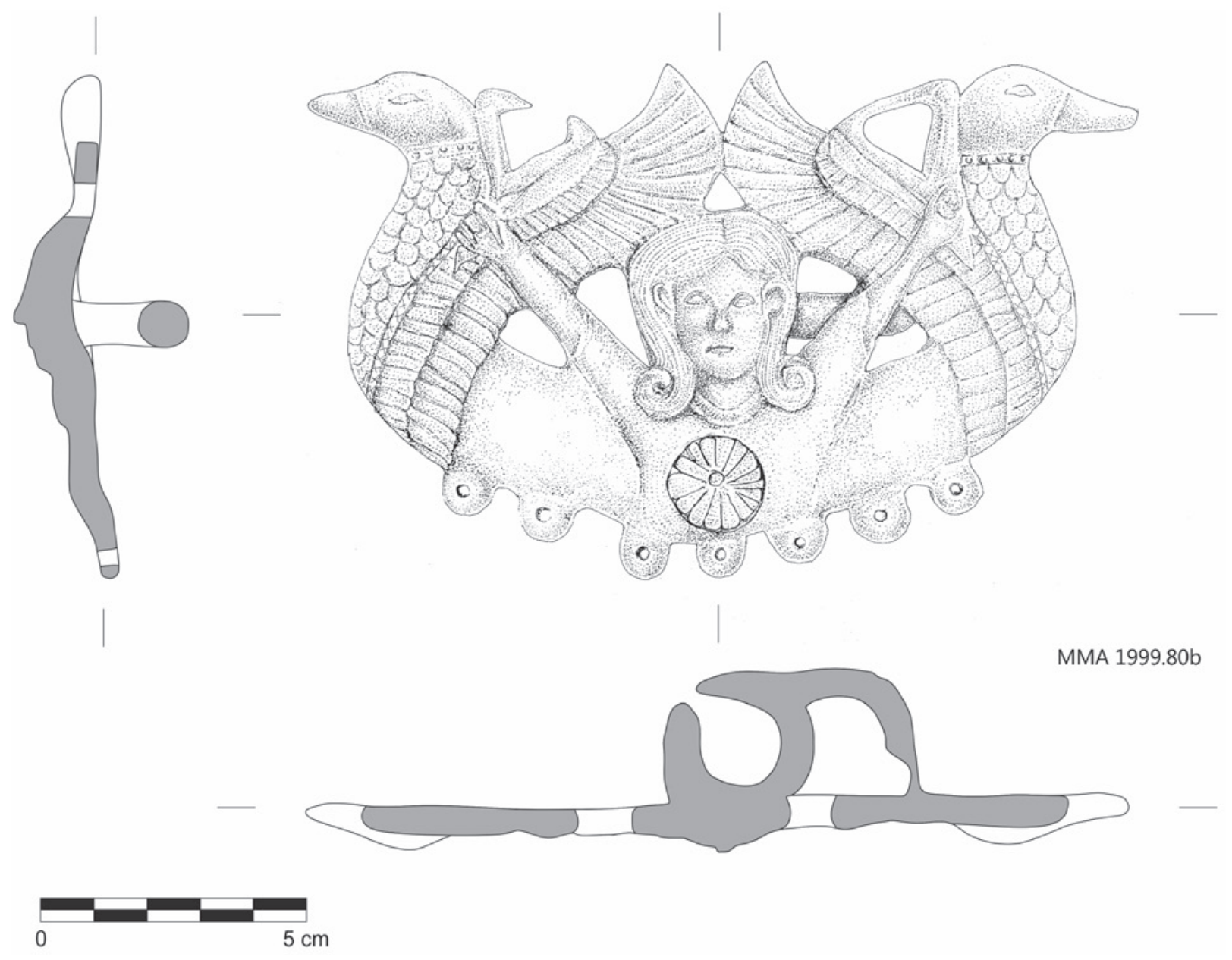

Fig. 3. Dibujo de la placa 1999.80b, vista frontal y secciones (J. Jiménez Ávila-J. M. Jerez). 


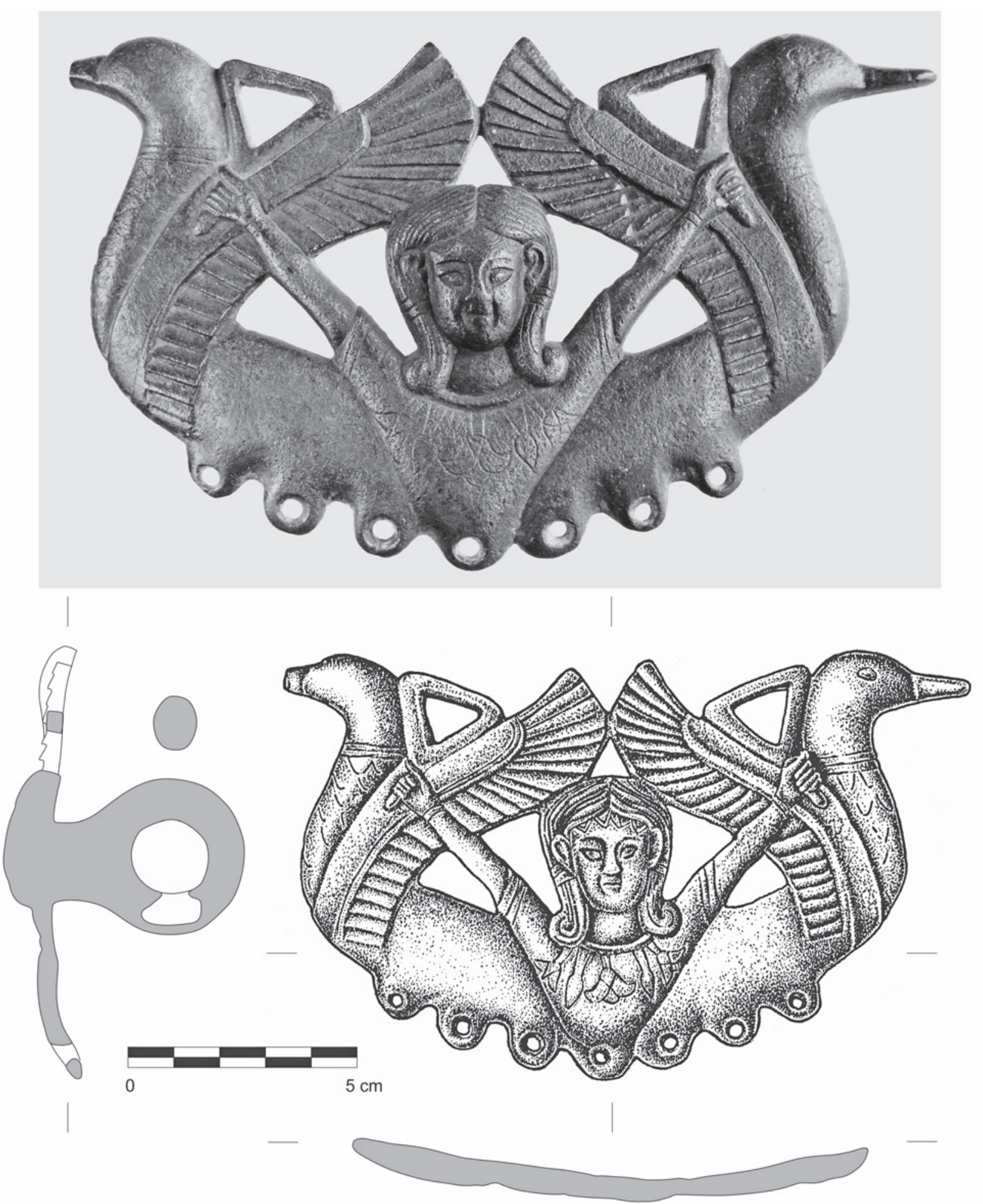

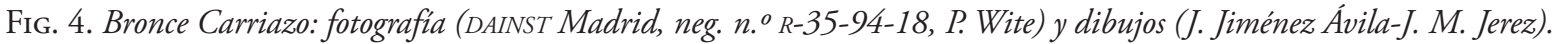




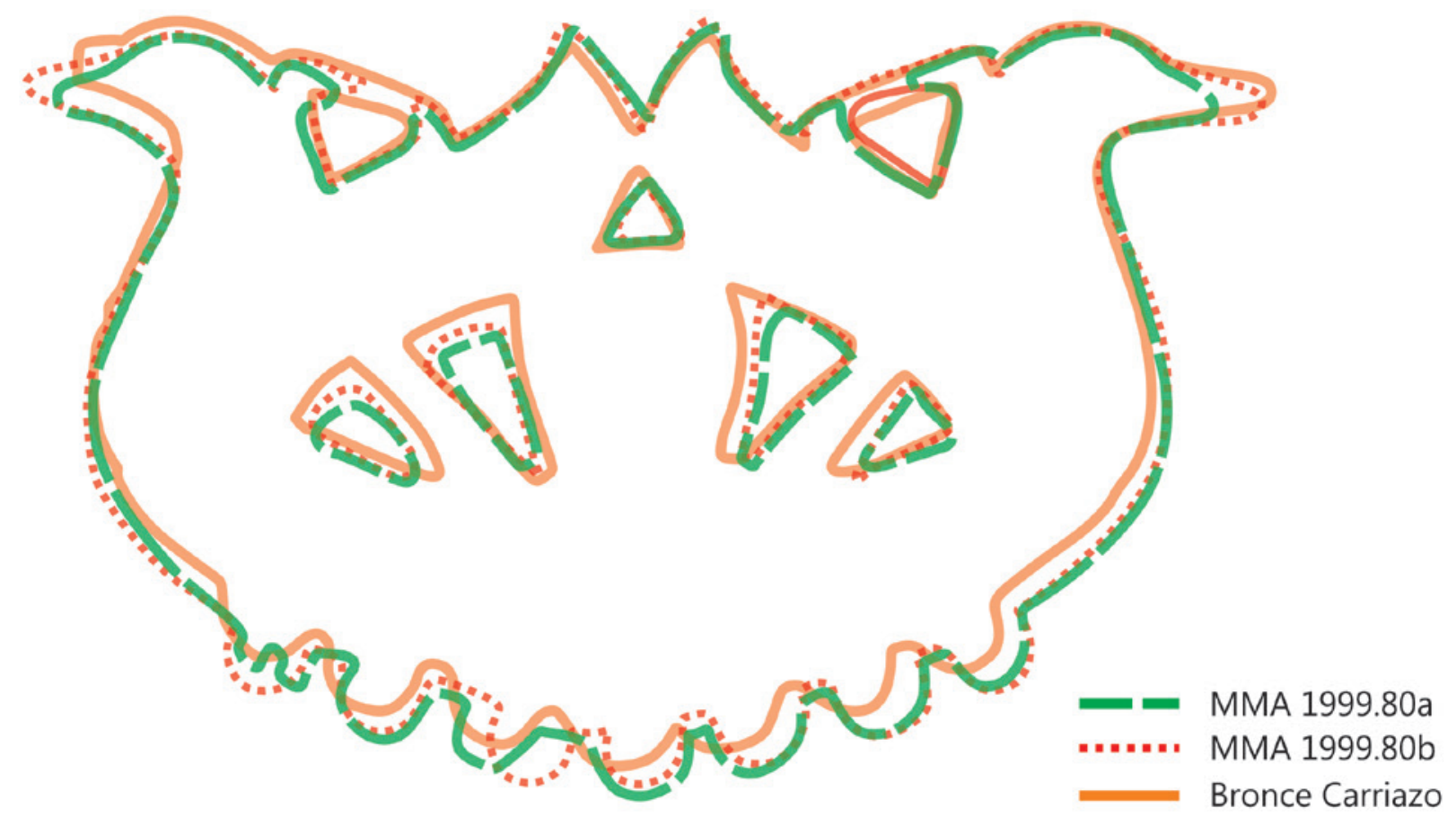

Fig. 5. Comparación entre las siluetas del Bronce Carriazo y las placas del MMA; los contornos se han obtenido directamente sobre las piezas.

quedando lisos los cuartos superiores de los alones, al otro lado de las manos, que discurren junto a los asideros triangulares. La decoración de los alones de las aves y su collarín de troqueles se unen así a los rasgos que hemos constatado en los rostros de las imágenes femeninas y, sobre todo, a la presencia de la roseta central en el lugar del collar de flores, como los elementos iconográficos más sobresalientes que diferencian estos bronces del MMA del Bronce Carriazo (Fig. 4), unos elementos que, en conjunto, permiten establecer entre ambas composiciones un estrechísimo aire de vecindad. A ello contribuye, además, la gran similitud que se obtiene al comparar las siluetas de las tres figuras que, aun tratándose de producciones individuales con sus rasgos propios, podrían proceder de una misma matriz originaria (Fig. 5).

De cara a la valoración y, sobre todo, a la comprensión funcional de estos dos objetos resulta fundamental referirse a sus partes traseras (Fig. 6), que actualmente aparecen recubiertas de una costra de barro fuertemente adherida que, no obstante, no impide observar sus componentes principales. Las superficies, prácticamente planas, presentan como único elemento sobresaliente unas anillas dobles de disposición horizontal en las que ya reparara Corzo (2007: 39), si bien el hecho de estar basado su trabajo en una observación desde la vitrina le impide realizar una descripción pormenorizada de las mismas. Estas anillas, de sección inicialmente circular, brotan de la parte trasera de la cabeza de las figuras femeninas, yendo a unirse con las aves en la zona donde las alas confluyen con el brazo humano. Las dos anillas son prácticamente iguales, con algunas diferencias de calibre debidas al proceso de fabricación manual, y de aspecto actual, producto estas de desgastes diferenciales. Pero lo más destacable es su situación especular, pues mientras que la de la pieza 1999.80a une la cabeza central con el pájaro de la izquierda, la b hace lo propio con el de la derecha, de manera que, en su disposición funcional paralela, en tanto que camas laterales de freno ecuestre, 

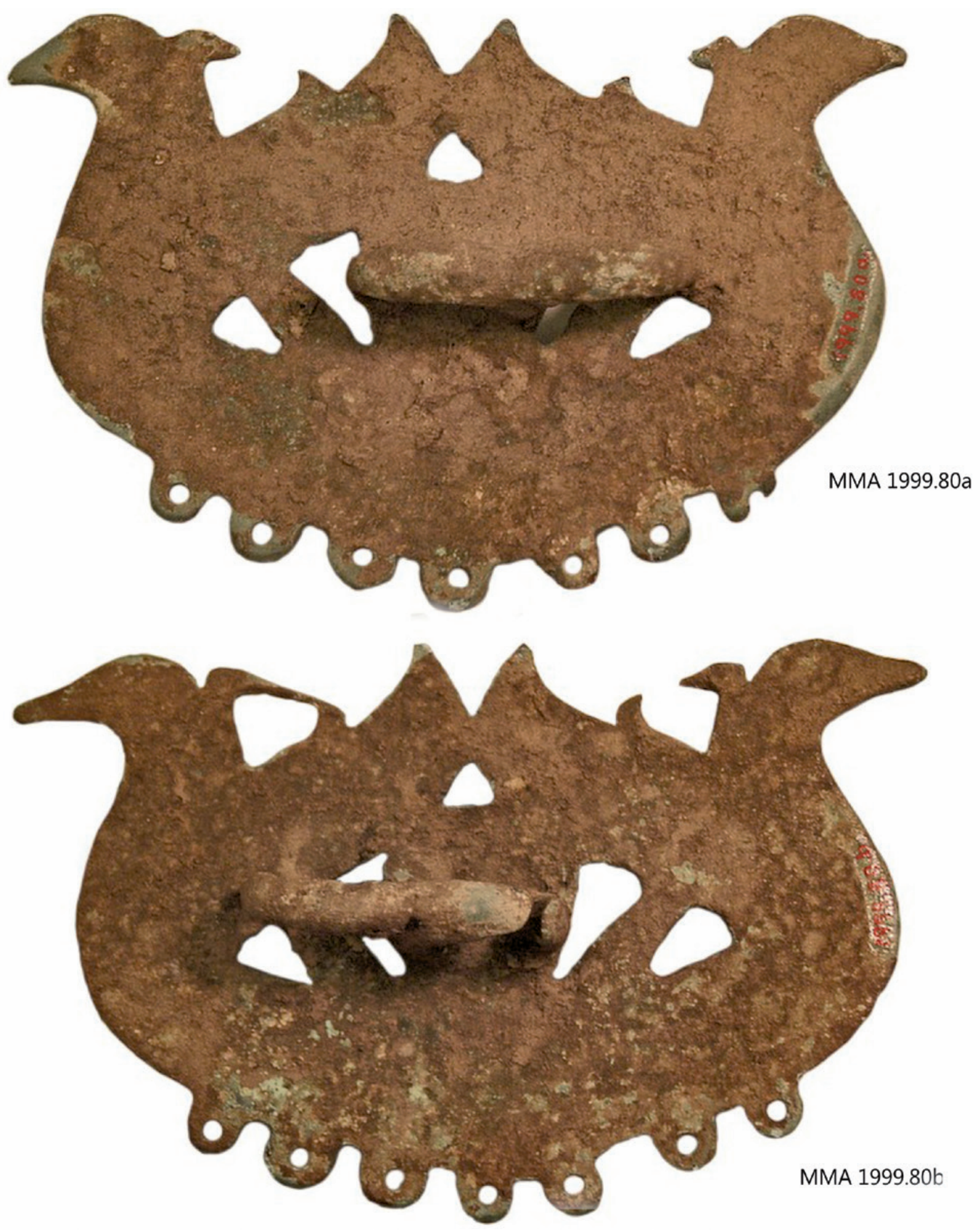

FIG. 6. Vista trasera de las placas del MMA mostrando las argollas de sujeción del filete y las riendas (fotografía J. Jiménez Ávila). 


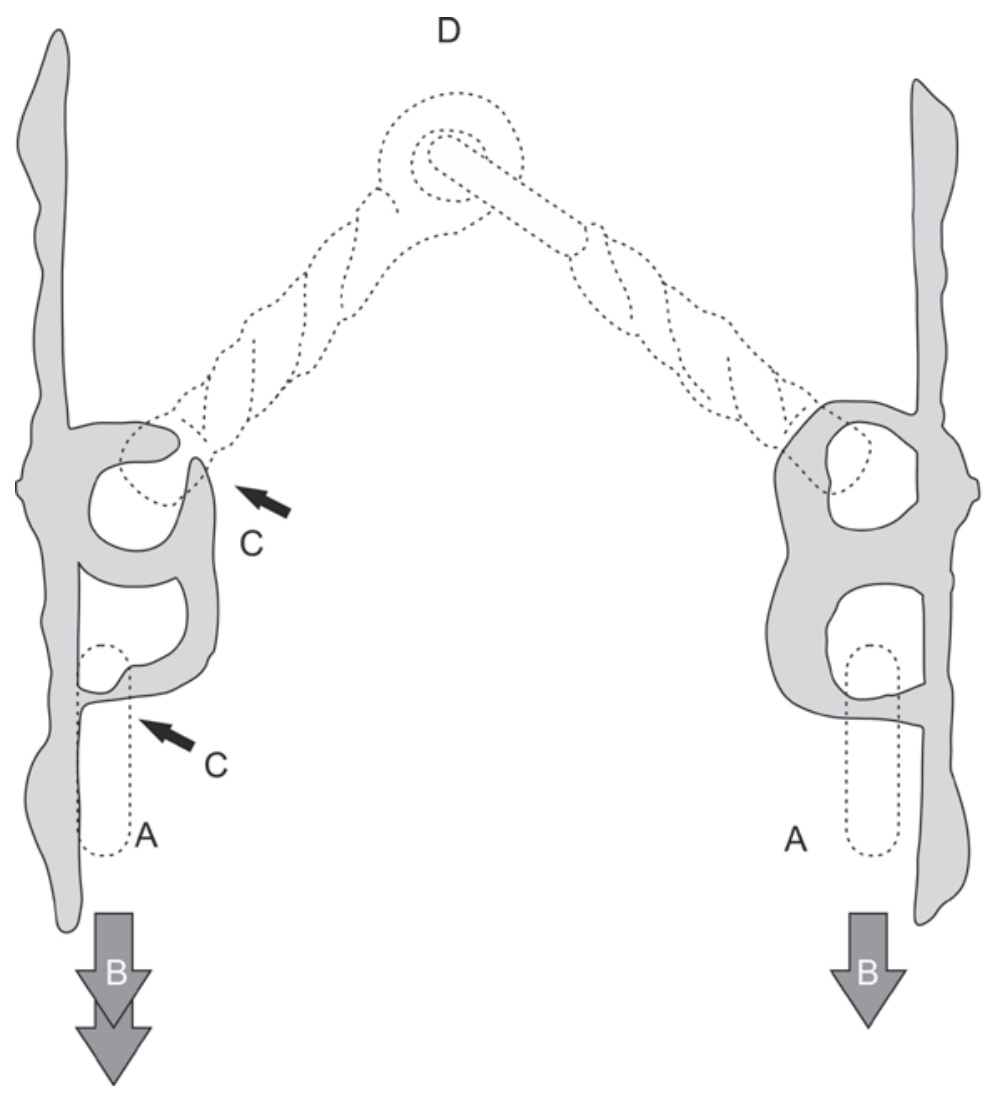

Fig. 7. Esquema de funcionamiento de las placas del MMA justificando los desgastes (vista superior): A) anillas o suplementos de riendas; B) dirección de las riendas; C) puntos de máxima tensión y desgaste; D) filete articulado.

los dos sets de anillas quedan emparejados (Fig. 7). Estas anillas dobles, de disposición horizontal, suponen una importante diferencia técnica respecto al Bronce Carriazo, que solo cuenta con una única anilla vertical (Maluquer de Motes, 1957: fig. 4; Carriazo, 1973: fig. 18; Marín y Ferrer, 2011: fig. 2). La explicación funcional de su estructura bipartita debe relacionarse con la disposición por separado de los agarres del filete y de las riendas, tal y como parecen denunciar las zonas de desgaste (Fig. 7), que, no obstante, presentan comportamientos diferenciales entre las dos placas, que pueden atribuirse bien a una reacción diferencial del caballo ante la acción del jinete o bien a que este animal ocupara la posición izquierda de la yunta de un carro. Ambas uniones se complementarían con argollas metálicas que se han perdido, no de otra manera se explicaría el profundo desgaste que ha sufrido el bronce.
En alguna ocasión se ha afirmado que la disposición de la anilla del Bronce Carriazo podría ser lesiva para el confort de los animales debido a su tamaño y a su anómala orientación vertical (Jiménez Ávila, 2002: 227; Marín y Ferrer, 2011: 623). La disposición horizontal de los agarres de los bronces del MMA podría resultar menos gravosa, si bien genera un apéndice muy ancho para ser introducido en la boca de la montura. Pero lo más probable, a la vista del conjunto de las tres piezas, es que los agarres unidos al bocado quedaran fuera del muerdo del caballo, que solo se ceñiría al cañón del filete, evitando así los posibles daños que las sujeciones fijas pudieran producir. No debemos olvidar, en todo caso, que todos estos inconvenientes derivan de la anómala condición de estas camas, que son macizas y no perforadas - para ser atravesadas por los filetes-, como es habitual en el atalaje ecuestre 
antiguo, aunque existen casos conocidos de camas con agarres fijos para el filete en Oriente y el Mediterráneo (Littauer y Crouwel, 1979: figs. 79 y 84). También conocemos más casos para el orientalizante hispánico, como una cabezada procedente de la comarca extremeña de La Serena conservada en el Fondo Arqueológico Ricardo Marsal Monzón -en adelante FARMM- del Museo Arqueológico de Sevilla, a la que enseguida volveremos a referirnos (Jiménez Ávila, 2020). Es muy posible que la forma de la anilla del Bronce Carriazo aunara las dos funciones que aparecen disociadas en los bocados del MMA, de manera que la argolla propiamente dicha sirviera para sujetar el filete y el tronco que la une a la placa acogiera la argolla o el suplemento de las riendas, algo que explicaría la gran separación entre anilla y placa, en una solución no muy alejada de la que plantean M. C. Marín y E. Ferrer (2011: 623) en su estudio del Bronce Carriazo que el conjunto del FARMM, dotado de unos gruesos suplementos ancoriformes, parece venir a refrendar (Fig. 8).
El estado de conservación de estas placas merece un comentario adicional por cuanto puede afectar al uso de las mismas, ya que la pérdida del travesaño de los agarraderos triangulares en tres casos -los dos de la placa a y el izquierdo de la b-inutilizarían su función, al menos en su concepción originaria, donde estos asideros sujetarían las correas de unión a las quijeras. Las anillas internas también están muy desgastadas. Esta circunstancia podría sugerir que las piezas estuvieran ya desechadas en el momento de su abandono, pero su hallazgo conjunto -aunque no se conserva el filete- apunta más bien hacia lo contrario, generando problemas de funcionalidad que pueden encontrar varias -aunque no obvias- soluciones.

Desde el punto de vista técnico las placas del MMA están fundidas a la cera perdida sin concurrencia de elementos soldados, como a veces se ha afirmado erróneamente, ya que la soldadura es impropia de los bronces mediterráneos de esta época. Los filetes se unirían, muy probablemente, mediante

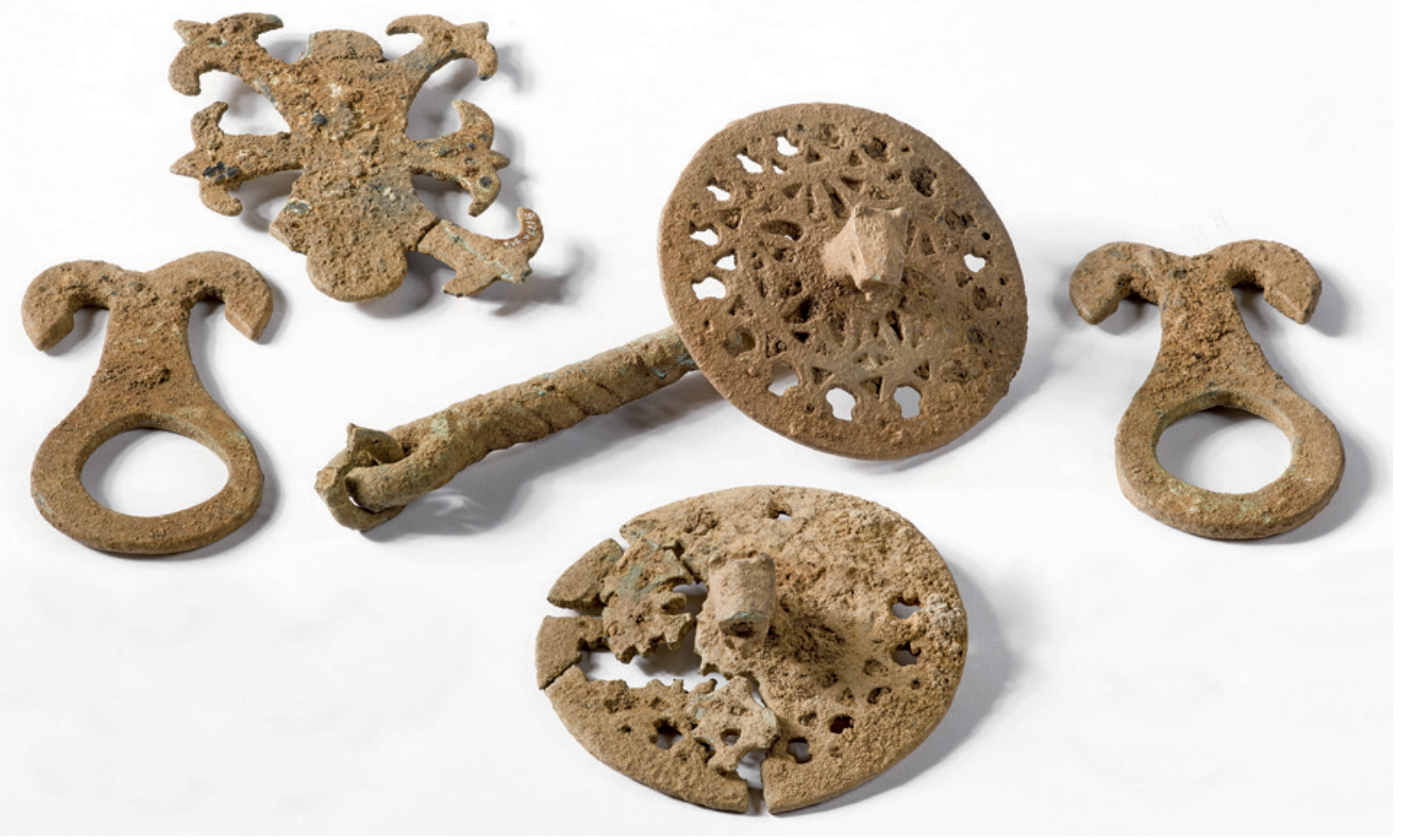

FIG. 8. Conjunto de bronces correspondiente a una cabezada equina de Época Orientalizante hallado en la comarca de La Serena, Badajoz, conservado en el FARMM (fotog. de M. García). 
la apertura de las anillas proximales, como hemos constatado en el ya referido bocado extremeño del FARMM, y en modo diferente a como se trabajan los bocados posteriores, donde las uniones se realizan por sobrefundido, quedando las argollas totalmente cerradas una vez se obtiene la pieza completamente acabada -ver, por ejemplo, Jiménez Ávila, 2018a-. El trabajo en relieve estaría realizado sobre el modelo de cera, pero es más posible que parte de la decoración incisa se trazara ya en frío, una vez desbastado el metal, algo especialmente claro en el caso de los troqueles circulares, pero igualmente aplicable a parte de la decoración incisa, probablemente realizada a buril.

Los procedimientos técnicos seguidos en estas piezas son, por tanto, los mismos que corresponden a toda la broncística fenicia occidental (Jiménez Ávila, 2002: 328 y ss.) y coinciden con los que se desarrollaron para fundir el Bronce Carriazo. Ya hemos señalado la gran similitud -no identidad-que se produce entre los perfiles de las tres piezas, lo que sugiere que, en origen, pudieran proceder de una matriz común (Fig. 5). No obstante, los acabados finales presentan especificidades propias -muy notables, por ejemplo, en el modo de tratar las lengüetas perforadas inferiores, como ya reseñara Corzo- que disuaden de considerar que se hubiera usado un mismo molde para obtener directamente los positivos de cera en los tres casos.

Resulta necesario referirse a dos afirmaciones que se han realizado en algunos trabajos previos referidas a las placas del MMA que, recordémoslo, tenían como única base documental las fotografías obtenida a través del cristal de la vitrina de la sala del museo. En primer lugar, su condición de réplicas o recreaciones contemporáneas del Bronce Carriazo que defiende R. Corzo, con militante convicción, en su trabajo de 2007, un planteamiento al que ya se han opuesto algunas pertinentes objeciones (Marín y Ferrer, 2011: 629). Bajo nuestro punto de vista, los argumentos esgrimidos, primordialmente estilísticos, adolecen de una considerable endeblez y son deudores de un amplio margen de subjetividad. Es cierto que, en algunos recursos técnicos y decorativos de las placas del MMA, parecen debidos a manos menos expertas que las que trabajaron la placa del MASE -es especialmente evidente en el tratamiento de las plumas remeras de la placa a, sobre todo-, pero nada autoriza a pensar que estas diferencias, que se desenvuelven más en la esfera del matiz que en el del insalvable escalafón, se deban a otra cosa que al distinto nivel de pericia que exhiben dos operarios diferentes dentro de la misma tradición artesanal, algo que en el ámbito de la toréutica fenicia-occidental resulta bien patente cuando, sin ir más lejos, se comparan la amplia variedad de calidades que exhiben las múltiples máscaras hathóricas recuperadas en la Península Ibérica, o las figurillas que sirven como cariátides en los timiaterios que las usan como soporte de las cazoletas (Jiménez Ávila, 2002: fig. 339), que, por su condición todas ellas de representaciones femeninas, son especialmente ajustadas a una comparación con las figuraciones de nuestros bocados. También señala Corzo que se detecta en las figuras del MмA “... un cierto gusto a recargar la decoración...” que -añadimos nosotros- suele ser moneda de curso común en las réplicas contemporáneas. Esta tendencia es aceptable para las aves, pero no para las diosas, que en el caso de las placas del MMA aparecen desprovistas de varios de los aditamentos que portan las del Bronce Carriazo, como hemos tenido ocasión de comprobar. Además, los elementos elegidos para esta barroquización -las sucesiones de troqueles circulares, a veces enmarcados entre líneas horizontales y las alineaciones de aspas que aparecen en las alas- son recursos muy característicos de la broncística orientalizante peninsular, y los encontramos en piezas emblemáticas como el jarro de La Zarza, los timiaterios de La Lagartera, Higuerones y Villagarcía de la Torre (Jiménez Ávila, 2002), o en los más recientemente publicados de la Colección Cervera (Jiménez Ávila, 2018b). Y resulta poco aceptable que un copista actual haya recurrido a estos motivos tan típicos cuando la mayoría de estos objetos eran desconocidos en el momento en el que comenzaron a circular estas placas; un momento, además, muy anterior a la sistematización de la toréutica orientalizante peninsular. Porque Corzo se ciñe a recoger el dato que aparece en la cartela de la vitrina del 
Metropolitan, en la que se indicaba que los bronces ingresaron en el museo en 1999 por donación del matrimonio Sackler, pero no indaga en el recorrido museográfico anterior, que sitúa las piezas en anticuarios europeos ya en los años sesenta del s. xx, tal y como reflejan los registros de dicha institución. Este dato adquiere importancia per se, porque el Bronce Carriazo empieza a ser una pieza célebre a raíz de su inclusión en algunas publicaciones que alcanzan mayor difusión que las primeras noticias de Maluquer de Motes (Maluquer de Motes, 1957), como el $V$ Symposium Internacional de Prehistoria Peninsular (1968) o, sobre todo, la obra de J. de M. Carriazo sobre Tartessos y el Carambolo (1973: 32-47). Por eso, es difícil pensar en una réplica tan temprana.

Pero, si todos estos argumentos estilísticos tienen bastante peso, creemos que los de corte técnico son aún más definitivos. Señala Corzo (2007: 39) que con la disposición horizontal de las dobles anillas "... las placas quedarían trabadas sin posibilidad de articulación...”. Ya hemos expresado nuestra opinión sobre cómo funcionan estas anillas en relación con los elementos del freno y la cabezada y cómo quedarían perfectamente articuladas. Pero lo que resulta poco o nada verosímil es que este procedimiento único, que requiere de unos conocimientos importantes en los sistemas de control de las caballerías antiguas y actuales y que supone una mejora sobre el sistema del Bronce Carriazo, haya sido recreado por un falsificador contemporáneo, con sus correspondientes y congruentes huellas de desgaste, al intentar imitar dicha pieza.

Incluye, por último, Corzo en su propuesta las fotografías de algunas réplicas recientes del Bronce Carriazo, salidas del afamado taller hispalense de Marmolejo, como evidencia de que las placas del MMA son, igualmente, recreaciones contemporáneas debidas a un artesano de menor pericia. La prueba, a nuestro juicio, es más bien redarguyente, pues lo que se observa en dichas réplicas es, precisamente, el uso de técnicas diferentes a las antiguas, como, por ejemplo, el trabajo de todo el repertorio decorativo directamente en el modelo de cera, lo que genera unas líneas en el bronce que aparecen más como profundos surcos o depresiones que como finas líneas de buril trazadas en frío, tal y como, por el contrario, se observan en el Bronce Carriazo o en los bocados del mMa que aquí nos interesan. Estos procedimientos dan un aire de distintiva familiaridad a las múltiples réplicas de la célebre pieza sevillana que han proliferado en los últimos tiempos y que, encabezadas por la escultura king size que hoy preside una de las rotondas de acceso a la localidad de Camas, afloran en internet a poco que se teclee la secuencia 'Bronce Carriazo'.

La segunda afirmación que antes mencionábamos se refiere a la posibilidad de que las placas del MMA sean productos orientales, como sugieren $\mathrm{M}$. C. Marín y E. Ferrer (2011: 618) en su estudio del Bronce Carriazo y que los lleva a plantear la posibilidad, por analogía, de que la propia pieza sevillana fuera también un producto oriental. En este caso, de nuevo, la documentación del MMA, que les atribuye un origen peninsular, nos saca de dudas. Por otro lado, resulta infrecuente el hallazgo de objetos tan similares procedentes de los extremos del Mediterráneo, sobre todo cuando se trata de complejas composiciones figurativas, como es el caso. Por último, hay que referir que en toda la iconografía fenicia que se desarrolla en Occidente se registran componentes técnicos y figurativos que permiten disociarla de las producciones orientales y reconocerla, en términos generales, como una producción fenicia provincial (Jiménez Ávila, 2002; 2015). El recurso a técnicas decorativas sencillas, como la incisión o la impresión, en lugar del trabajo en relieve, o el tratamiento más sumario de las figuras, que les confiere un cierto aire ingenuo o primitivo, permiten distinguir estas producciones coloniales, sobre todo en bronces y marfiles, donde, no obstante, se reconocen productos elaborados con diferente grado de calidad. A estas directrices técnicas e iconográficas, que permiten definir las producciones fenicias occidentales o hispano-fenicias, se adecuan perfectamente tanto el Bronce Carriazo como la pareja de bocados del MMA, por lo que su condición de producciones hispánicas debe quedar, en el estado actual de nuestros posicionamientos investigadores, fuera de cualquier duda. 
La cronología del Bronce Carriazo se ha situado entre el 700-600 a. C. (Jiménez Ávila, 2002: 229); 700-500 a. C. (Torres, 2002: 344); 625-575 a. C. (Maluquer de Motes, 1957: 164; Blázquez, 1975: 103; Almagro Basch, 1979: 189); 600 a. C. (Almagro Gorbea, 1977: 229; Ruiz Mata, 1994: 392, fotog. 2, 419), o 600-500 a. C. (Blázquez, 1983: 42). La gran similitud de los bronces del mMA con esta pieza sugiere una coetaneidad prácticamente absoluta que habría que situar dentro de este marco que se desarrolla entre el 700 y el 500 a. C., inclinándonos por la primera de las dos centurias que este lapso comprende, a pesar de la lamentable descontextualización de los tres casos conocidos.

\section{Aspectos iconográficos}

La iconografía de estos bocados tiene cuatro elementos clave: una divinidad central con un peinado hathórico y dos cabezas de ánades a ambos extremos que parecen formar una embarcación con dos prótomos de aves. El cuarto elemento, las alas, lógicamente corresponde a los ánades que levantan vuelo, pero también podrían entenderse como parte de una divinidad que remonta el vuelo con ellas, mostrando que se trata de una divinidad alada, de las que encontramos algunos ejemplos en la Península Ibérica en época orientalizante. La roseta central presente en los bocados del Metropolitan sugiere una vinculación solar.

El peinado hathórico y la túnica egipcia eran utilizados por la diosa qdš qudšu (Boreaux, 1939: 673-676, figs. 1-3; 685, fig. 4; Edwards, 1955: 4951, lám. 3), la diosa extranjera más importante en Egipto, que se asimila con la cananea 'šrh 'Ašerah y a la ugarítica 'trt 'atrt Atirat (Albright, com. pers. a Edwards, 1955: 51, n. 20; Lipinski, 1972: 111-112; Cross, 1973: 33-35; Maier, 1986: 90-91, 194; Keel y Uehlinger, 1992/1998: 66 n. 7). Esta diosa se asimila como qdššs st- $n t$ en la estela del Winchester College (Edwards, 1955: 50), proponiéndose que en Egipto se trataría de una misma divinidad $q u$ dšu 'astart 'anat (Stadelmann, 1967: 99, 112-116, 119; Lipinski, 1986: 90) o bien una triada de diosas (López Grande, 1998: 149).
La divinidad del Bronce Carriazo ha sido considerada Hathor (Maluquer de Motes, 1968/1989: 122; García y Bellido, 1969: 163; Bosch Gimpera, 1975: 744; Ruiz Mata, 1994: 419; Corzo, 2007: 38), Astarté (Almagro Gorbea, 1977: 229; Blázquez, 1983: 42; Marín Ceballos y Ferrer, 2011: 638), Anat (Almagro Basch, 1979: 189, 191) o qudšu 'aštart 'anat (Blanco Freijeiro, 1960: 156), que es la propuesta que nos parece más correcta:

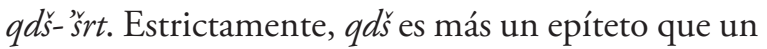
nombre de una diosa, porque en ugarítico, fenicio y hebreo significa 'sagrado' o 'santo', relacionable con la expresión hebrea qdš qadeš, persona sagrada, o incluso prostituta del templo, y a menudo aparece asociada en las estelas egipcias a řsp (Fulco, 1976: 16-17, 23). Qdšs suele aparecer desnuda, ’s $r$ t puede aparecer vestida o desnuda y 'nt-'Anat a menudo viste una túnica larga y transparente. En Egipto durante el Imperio Nuevo dos de estas diosas son guerreras, 's $r t$ y ' $n t$, y aparecen fusionadas como 'ntrt en el tratado entre Ramsés II por Egipto y Hattusili III de Hatti (Albright, 1968: 74), carácter guerrero que explica su presencia en estos bocados de caballo que también podrían ser parte del tiro de un carro. Una inscripción de época lágida o ptolemaica de Edfú, $c$. 323-330 a. C., en un carro presenta la inscripción "Astarté, señora de los caballos, la Dama del carro" (Lipinski, 1995: 139). Ejemplificando el carácter guerrero, las armas de Saul, el primer rey de Israel, y sus tres hijos muertos en monte Gelboé, fueron recogidas por los filisteos y "Depositaron sus armas en el tempo de Astarté" (1 Samuel 31, 10). La diosa es representada habitualmente sobre un caballo o sobre un carro de guerra (Leclant, 1960: lám. 4a-4b) y recibía ofrendas de caballos según una inscripción fenicia de Kition en Chipre (Puech, 1976).

La diosa qdš-'trt-šs rh, con peinado hathórico, puede usar túnica egipcia o más frecuentemente ir desnuda, portando en la mano derecha una flor de loto con tres pétalos (Pritchard, 1943: 35), loto que en la estela del Winchester College está pintado de color azul (Edwards, 1955: 50), y en la mano izquierda suele agarrar entre una o dos serpientes (Pritchard, 1943: 33-34), aunque a veces son sustituidas por otra flor de loto. Estas flores de loto, Nelumbo nucifera, una planta acuática presente en 
el río Nilo, simbolizan la belleza y elegancia, pero sobre todo la regeneración y la vida, pues la flor se abre al amanecer y se cierra durante la noche (Keel y Uehlinger, 1992/1998: 54), mientras la serpiente simboliza la fertilidad y la fecundidad (Albright, 1942: 76) por los huevos que pone bajo la tierra. La postura de los brazos levantados en forma de ' $v$ ' ha sido relacionada por Maier (1986: 85, 131, n. 38) con una representación simbólica de la región genital femenina. Sin negar este aspecto, los brazos levantados entre la cabeza, y más en estos bocados donde no se representa el cuerpo, pueden representar a su vez el sol entre los cuernos de Hathor, y las flores de loto que rematan esta ' $v$ ' tienen el mismo comportamiento que el sol, renacimiento por la mañana y ocaso por la noche.

Las flores de loto se representan en el Bronce Carriazo formando parte de un posible collar en el cuello de la diosa, alternando capullos de flores cerradas y abiertas, pero no aparecen en el par del MMA. Estos, en cambio, presentan grabados sobre el pecho una roseta de 16 pétalos que suele asociarse con Astarté (Escacena, 2011-12: 161-162) y evoca el disco solar que, en similar posición, portan algunas representaciones orientales y occidentales, como evidencia el peine de marfil del conjunto $85 \mathrm{~B} / 36 \mathrm{de}$ Medellín (Almagro-Gorbea, 2008: 418-425, 419, fig. 540).

Desde el punto de vista funcional, las aberturas triangulares de la parte superior deben considerarse como sujeciones de las correas de la cabezada, a lo que contribuye su disposición oblicua. Su interpretación iconográfica, sin embargo, no ha sido unánime, siendo interpretadas generalmente como flores de loto (Maluquer de Motes, 1957: 160; Blanco Freijeiro, 1960: 155; Blázquez, 1975: 102, 104 y 1983: 42; Marín Ceballos y Ferrer, 2001: 629), repitiendo el modelo de la ya citada diosa de $\mathrm{Me}-$ dellín (Fig. 9, n. ${ }^{\circ} 1$ ) o de la Astarté del monumento de Pozo Moro (Fig. 9, n.o 2) que sujetan una flor de loto en cada mano (Almagro-Gorbea, 1978: lám. 4; Blánquez, 1999: 269, fig. 226d). Otras opiniones, en cambio, se inclinan por que fueran dos sistros, por su relación con Isis (Olmos et al., 1992: 69, n. 27/2; Jiménez Ávila, 2002: 339; Almagro-Gorbea, 2004: 38 y 2008: 420), que se argumentan por
Olmos como un 'instrumento de percusión, tintineante, de su culto epifánico'. La silueta triangular de los objetos que empuñan las diosas es poco compatible con la forma del tallo de una flor que, por otra parte, se podría haber trabajado completamente sin anular su función de agarraderros. Por otro lado, la iconografía de diosas con dos sistros (instrumento más compatible con este mango) es desconocida, por lo que se trata, en ambos casos, de una interpretación no exenta de problemas.

Existe la posibilidad de que las alas se relacionen con la diosa pues, como se ha sugerido (Jiménez Ávila, 2002: 230; Corzo, 2007: 38), las tres líneas en el cuello que tienen los prótomos de aves en el Bronce Carriazo podrían ejemplificar que están sujetas por la divinidad para controlar su vuelo, incluso Maluquer de Motes (1957: 158 y 1968/1989: 122) considera las tres líneas parte de un collar o collarín. Esto parecen apoyarlo las dos piezas del MMA que en vez de líneas presentan una banda con pequeños círculos a modo de collar. Aun cuestionando que los ánades estén agarrados como plantean Marín y Ferrer (2001: 636, n. 79), iconográficamente las alas de los ánades cumplen la misma función. Las divinidades aladas sagradas protegen con sus alas y sirven para transportar al ámbito celeste el cuerpo de un difunto, importante si los bocados proceden de enterramientos, la opción más lógica. Como señalan los salmos en la Biblia (Ubieta, 1994), "con tus plumas te cubre, y bajo sus alas tiene un refugio: escudo y armadura" (Sal.-Ps., 91, 4).

Hay dos representaciones en el Bronce Final, una de Kültepe (Anatolia), c. 1700 a. C., donde una diosa femenina desnuda, con peinado hathórico, sujeta un ave en cada mano, estando coronada por el sol alado (Fig. 9, n.o 3). Este motivo es muy parecido en una terracota de Alalach, c. 1300 a. C. (Fig. 9, n. $\mathrm{O}$ 4), con la única diferencia de que no presenta el peinado hathórico (Winter, 1983: fig. 290 y 291). Ya en el periodo Protogeométrico Final en Creta, 950-900 a. C., un pithos de Knossos del cementerio Norte, tumba 107, muestra una diosa alada agarrando un ave en cada mano (Fig. 9, n. ${ }^{\circ}$ 5), dispuesta sobre un carro, que se considera una Afrodita o posiblemente Astarté (Coldstream, 1984: 94-97, 96, fig. 1 y 98, fig. 2). Como divinidades celestes, 

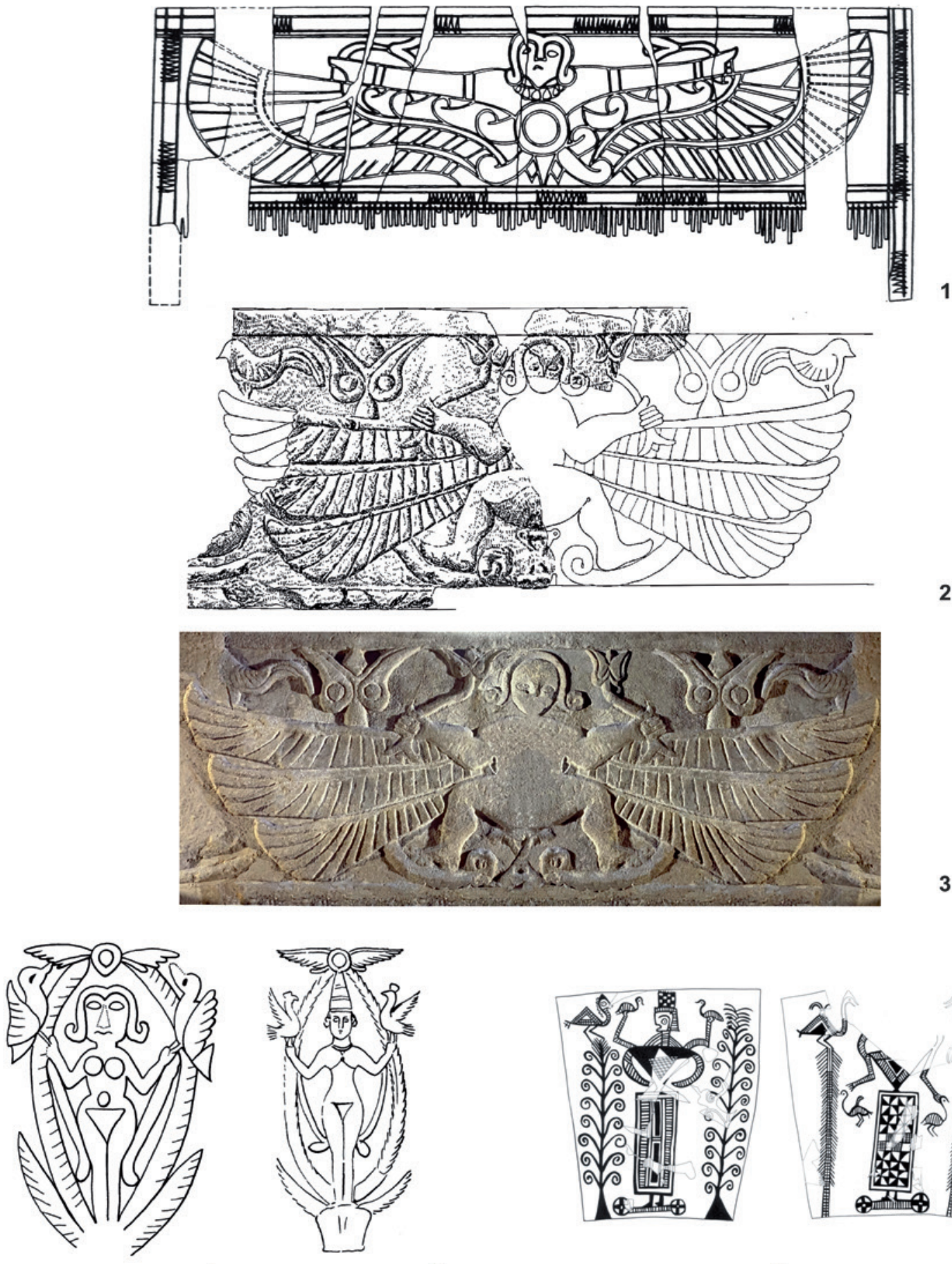

4

5

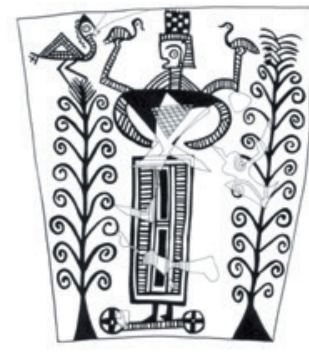

6

Fig. 9. Diosas aladas con pájaros y flores de loto del Mediterráneo antiguo: 1) peine M2 de la necrópolis de Medellín, Badajoz (Almagro-Gorbea et al., 2008); 2) reconstrucción de la diosa de los relieves de Pozo Moro, Albacete (Blanco Freijeiro, 1981); 3) montaje fotográfico reconstructivo de la misma figura (Blánquez, 1999); 4) Kültepe; 5) Alalakh (ambas en Winter, 1983); 6) pithos protogeométrico de Knossos, Creta (Coldstream, 1984). 


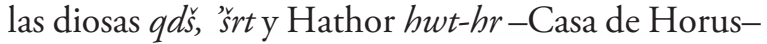
son señoras del cielo (Tazawa, 2014: 111). Astarté concretamente era la "Reina de los Cielos" (Jr, 7, 18). El problema es la identificación del tipo de ave presente en los bocados asociada a la divinidad. En el caso de šr $r$ se materializa como una codorniz (Coturnix coturnix), en la que fue convertida por Zeus al rechazar sus proposiciones (Lactancio, ad. Stat., Iv, 795; Hygin., Fabulae, LIII; Bonnet, 1988: 20 y 1996: 37). Como codorniz, con su hálito, devolvió la vida a Melqart cuando fue muerto por Tifón. Según 'Eudoxo de Cnido (...) los fenicios sacrifican codornices a Heracles, debido a que (...) fue muerto por Tifón cuando recorría Libia, pero volvió a la vida al oler una codorniz que Yolao le había traído y puesto a su lado' (Athen., Ix, 392d-e). No obstante, el cisne puede estar consagrado a Venus Urania o Caelestis, tirando a veces de su carro, y puede asociarse con Astarté por su relación con Afrodita. No puede ser la diosa Isis porque era representada como un ave rapaz (López Grande y Trello, 2004), un milano real-Milvus milvus- o como un halcón -Falco biarmicus - al igual que Horus hor. Una corneja negra-Corvus corone- aparece asociada a Atenea en Corone (Paus., Iv, 34, 6). Por otra parte, no debe olvidarse que, en la mitología egipcia, al morir el Ba deja el cuerpo en forma de pájaro (Goedike, 1970), que era también el signo con que se representaba en la escritura jeroglífica, inicialmente a partir del jabirú africano con un largo pico (Ephippiorhynchus senegalensis), mientras el Ka permanece en la tumba y en caso de desaparecer el cuerpo puede materializarse en una estatua del fallecido, pues cada noche el Ba debía regresar al cuerpo del difunto.

Las aves de nuestros bocados han sido consideradas patos (Carriazo, 1957: 157; Blázquez, 1975: 102-103 y 1983: 42), o ánades (Maluquer de Motes, 1968/1989: 122; García y Bellido, 1969: 163; Olmos et al., 1992: 69, n.o 27/2; Ruiz Mata, 1994: 419; Corzo, 2007: 38; Marín Ceballos y Ferrer, 2011: 632, 635, 638), seguramente el ánade real -Anas platyrhynchos-, con un pico largo y recto, entre los cuales los machos tienen la cabeza con un azul muy intenso, aspecto muy interesante si los lotos fueran siempre azules pues también es el color del cielo y del agua, antes que cisnes blancos-Cignus olor- que tienen cuellos más largos y estilizados, citándose también genéricamente aves acuáticas (Almagro-Gorbea, 1977: 229) o la codorniz (Torres, 2002: 344) por la vinculación con šst. Por la posición central de $q d s^{y}-\stackrel{s}{s} r t$ en el centro del barco parece sustituir al sol, pues conforma con los ánades en proa y popa una barca solar, ya que el recorrido del sol tiene su amanecer o aurora en Oriente y su puesta u ocaso en Occidente. El barco solar, pues navega por el cielo que era de agua, simboliza por tanto el viaje al más allá, al extremo Occidente. La presencia de un sol que surge del cuerpo de la diosa alada en el peine de marfil M2 de la necrópolis de Medellín, fechado hacia el 675 a. C., que ha sido identificada con Astarté (Almagro Gorbea, 2008: 418-425, 419, fig. 540), apunta a este carácter solar de la divinidad femenina, aunque otros autores consideran que el sol alado sería un elemento independiente de la diosa, y estaría sobre su pecho o abdomen (López Pardo, 2006: 134-135). No obstante, es interesante que en el Bronce nórdico los enterramientos femeninos importantes desde el Bronce II, 1500-1325/1300 a. C., presentan una gran placa circular de bronce decorada, a modo de cinturón, a la altura del vientre como sucede con varios enterramientos de mujeres jóvenes durante el Bronce IIB (Kristiansen y Larsson, 2006: 331, 335), caso de Ølby, c. 1400 a. C. o Egtved, c. 1370 a. C.

Por otra parte, la diosa Hathor era la divinidad astral egipcia, 'señora del cielo' o 'señora de las estrellas', que daba nacimiento al sol cada mañana (Bleeker, 1973: 31-34, 46-47), pero también lo era del ocaso y del desierto de Libia, donde se pone el sol, pues recibía al muerto en la otra vida. Su representación más habitual tiene sobre la cabeza los cuernos en forma de barca solar con el sol en el centro, aunque los cuernos suelen asociarse normalmente a un bóvido con cuernos, como diosa del ganado que provee de leche y carne a los humanos y era su posesión más valiosa desde el Predinástico. Como puede observarse en una estatua de la Iv Dinastía, acompañada por el faraón Menkaure, en el Fine Arts Museum de Boston, ya los cuernos curvan hacia el exterior, y no como sucedía en la paleta de Narmer donde, de ser la diosa Hathor, los cuernos curvan hacia el interior. Estos cuernos también los 
tenía Astarté que a veces es denominada en la Biblia como 'Astarté de los cuernos', Ashtarot Qarnayim, o traducida al castellano como 'Ašterot Carnáyim' (Gen., 14, 5), con la raíz qrn en hebreo, Qarnayim, mencionada en la Biblia en el cielo e infierno de los reyes divinizados o rephaim (Prov., 9, 18; KAI 13, líns. 7-8). Consecuentemente, habría tres elementos acuáticos en esta iconografía, los lotos que flotan sobre el agua, normalmente ríos o lagunas, los ánades reales que también suelen estar en un ámbito acuático, y finalmente la barca solar, porque el cielo también es acuoso.

Esta idea de la barca solar en el Bronce Carriazo es apoyada por varios investigadores (Maluquer de Motes, 1957: 160-161 y 1968/1989: 122; Blázquez, 1975: 103 y 1983: 43; Jiménez Ávila, 2002: 339), aunque otros la rechazan como una semejanza de su silueta no intencionada (Blanco Freijeiro, 1960: 155; García y Bellido, 1969: 163), e incluso se ha sugerido que podría ser una solución funcional para dar mayor solidez al bocado (Marín Ceballos y Ferrer, 2011: 636). Se ha defendido que la barca solar existió en la Península Ibérica desde el Neolítico Final en una vaso de la cueva de la Murcielaguina (Priego, Córdoba) que presenta un soliforme (Escacena, 2011-12: 175, fig. 24 y 2015: 52 , fig. 13) y con mayor apoyo iconográfico durante el Calcolítico en cerámicas con representaciones solares y posibles barcos, identificados previamente como 'ramiformes', en cerámicas de Los Millares (Santa Fe de Mondújar, Almería) (Escacena, 201112: 170-172, fig. 20; 177-179, figs. 28-30; 184 y 2015: 51, fig. 11). Fuera del ámbito peninsular, su presencia también ha sido planteada para el Bronce Medio desde el descubrimiento en 1999 -pero recuperado en 2002- del disco de Nebra, Sajonia-Anhalt, Alemania, c. 1800 a. C. (Meller, 2010: 62 y 69, fig. 35). En esta pieza excepcional, se representó un posible barco solar (Meller, 2002: 10-14, 10, fig. 3 y 2004: 26, fotog. 3) añadido posteriormente al disco, c. 1650 a. C. (Meller, 2004: 28, fotogs. 1/3-4 y 2010: 47-48, fig. 14, 65-69, fig. 35), barco que navega en el océano del cielo (Maraszek, 2010: 488492, figs. 1-4). Los elementos principales son un sol como centro de la composición, una luna en cuarto creciente y 26 estrellas (Meller, 2002: 9 fig. 2;
Pásztor y Roslung, 2007: 276; Escacena, 2011-12: 158-166, fig. 14; Dathe y Kruger, 2018: 96-97, fig. 6), además de una agrupación de siete estrellas identificadas con las pléyades (Schlosser, 2002 y 2004 : 76, fig. 1, 78-79, 84, figs. 8-9). Esta propuesta nos parece correcta, frente a la interpretación como un cielo nocturno con luna llena, pléyades y luna en cuarto creciente (Schlosser, 2002, 2004: 76, fig. 1; 78 y 84, 2010: 930-931, figs. 25-26).

Tradicionalmente se había vinculado el origen de la barca solar del Bronce Carriazo con los Campos de Urnas del Bronce Final o a las culturas de Hallstatt durante el Hierro Inicial (Maluquer de Motes, 1957: 160; Blázquez, 1975: 104), asignándolo al sustrato mítico indoeuropeo (Carriazo, 1974/1980: 213; Almagro Gorbea, 1996: 74), pero otros investigadores han rechazado estas posibles conexiones centroeuropeas (Jiménez Ávila, 2002: 230). Se trata de un elemento iconográfico importante en la Europa interconectada del Bronce Final e Hierro Inicial, que se incorporó en tumbas principescas, fruto del intercambio entre élites, y refleja similares rituales de legitimación utilizando prácticas comunes del consumo de la bebida contenida en las sítulas (Kristiansen, 1998: 169-172, figs. 170-171). Sin embargo, en la Península Ibérica contamos con la representación de una barca con prótomos de aves en una de las sortijas del Tesoro de Aliseda (Almagro-Gorbea, 1977: lám. xxx), lo que obliga a valorar el origen oriental del tema en el contexto peninsular (Fig. 10, n. ${ }^{\circ}$ 1).

Los barcos con proa y popa con cabeza de ánades aparecen con los Pueblos del Mar que sirven para identificarlos desde inicios del siglo XII a. C. (Fig. 10, n. ${ }^{\circ}$ 2). En la batalla naval en el Delta del Nilo se representan en Medinet Habu cuatro barcos egipcios, presentando en la proa un prótomo de animal con forma de león o akroterion. Estas naves sorprenden a cinco barcos de los Pueblos del Mar fondeados en el delta, tres de los Prst Peleset y $T k r$ Tjekker con gorros de plumas (Fig. 10, n. ${ }^{\circ}$ 3) y dos de los $\breve{S}$ rdn Sherden (Fig. 10, n. ${ }^{\circ} 4$ ) con cascos de cuernos (Nelson, 1930: láms. 37 y 41). Los cinco barcos de los Pueblos del Mar tienen como identificador un doble akroterion con una cabeza de pájaro, tanto en la roda de la proa o akrostolion 

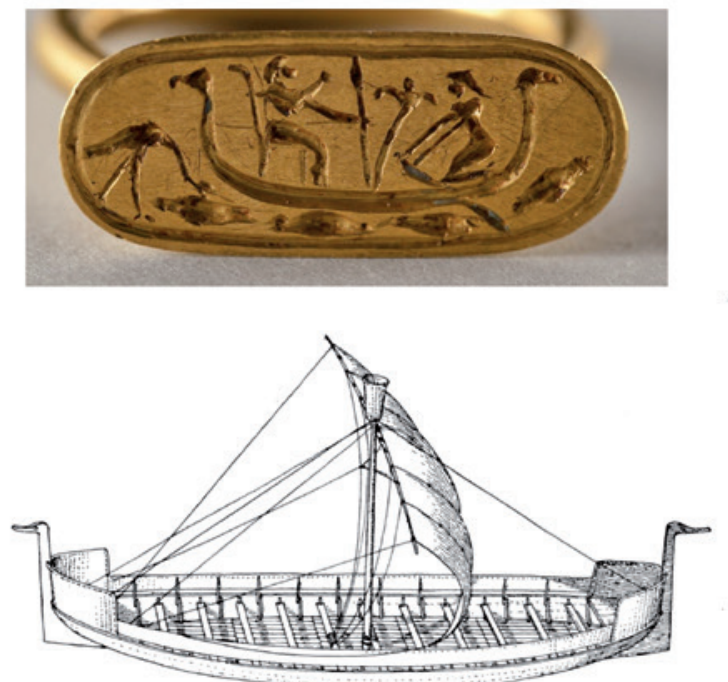

2
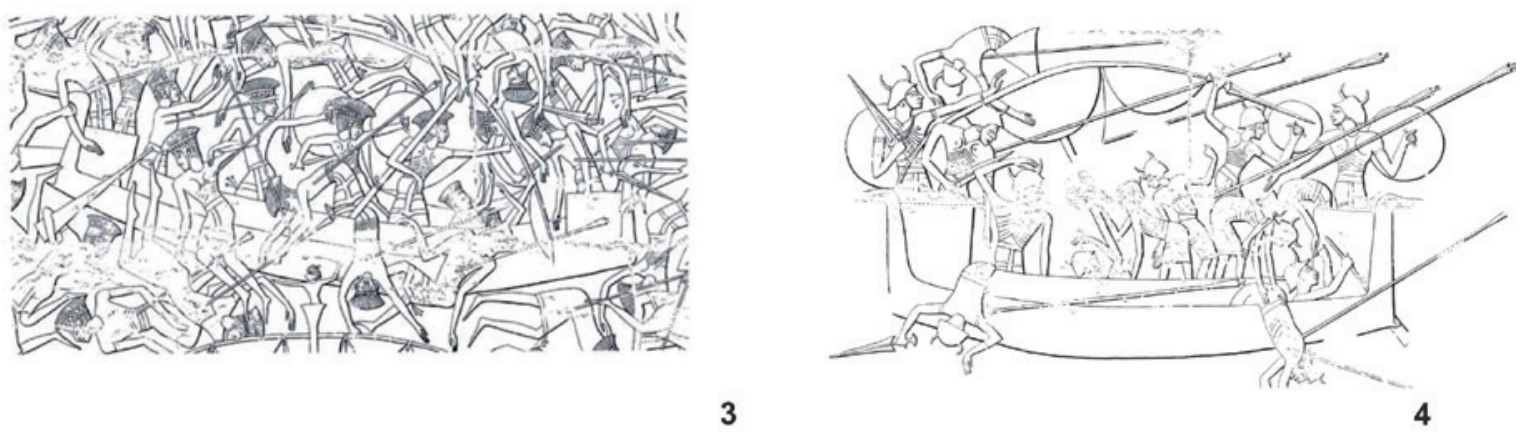

3
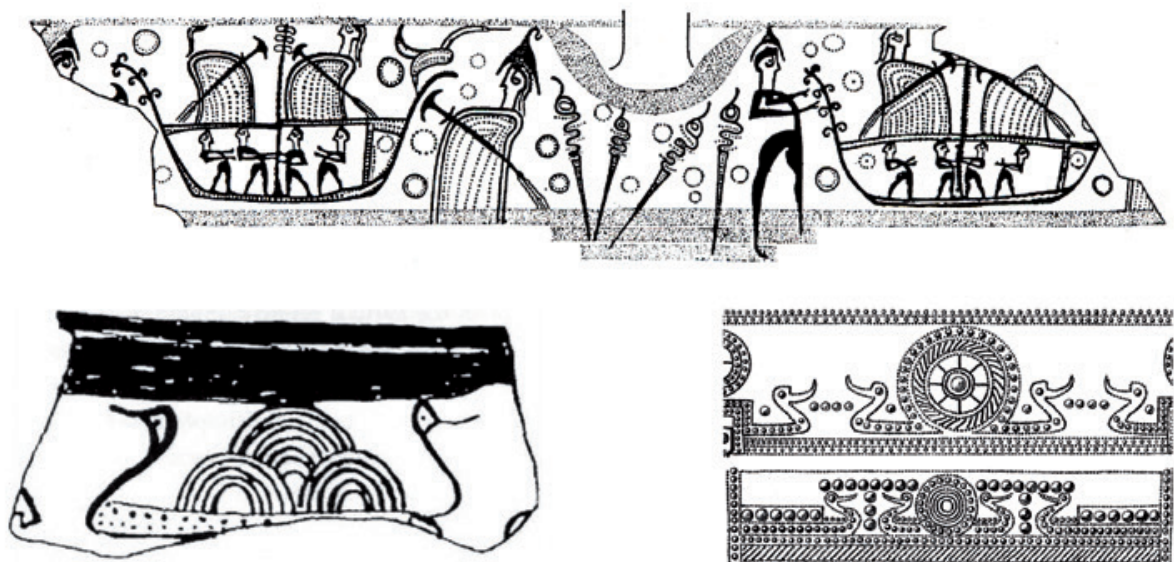

6

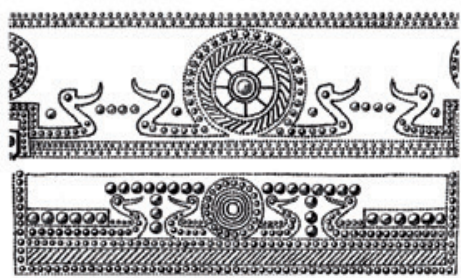

7

FIG. 10. Barcos y motivos barquiformes con prótomos ornitomorfos del Mediterráneo y Europa: 1) anillo-sello del Tesoro de Aliseda (foto MAN); 2) reconstrucción de un barco de los Pueblos del Mar (Landstrom, 1961); 3) relieve egipcio de Medinet Habu representando a los Peleset en combate naval; 4) relieve de Medinet Habu representando a los Sherden en combate naval (ambos en Nelson, 1930); 5) barcos con proa y popa elevadas, y akroterion con cabeza de ave en una crátera del Heládico Final IIIB de la tumba 3 de Enkomi, Chipre (Sjöqvist, 1940: fig. 20, n. ${ }^{\circ}$ 3); 6) crátera del Heládico Reciente IIIC-B de Tirinto (Slenczka, 1974); 7) urna metálica de Eslovaquia (Kossack, 1954). 
como en el codaste de la popa o aphlaston. Estos prótomos de pájaro eran característicos de los barcos de la Grecia micénica (Wachsmann, 1981: 210, fig. 25, 199, fig. 14), reconocibles desde el Heládico Final IIIB 1, en una crátera de la tumba 3 de Enkomi (Chipre) (Gjerstad, 1934: 484, n.o 282; Vermeule y Karageorghis, 1982: 45, fig. v.38), 1325-1225 a. C. (Fig. 10, n. ${ }^{\circ}$ ). Por otra parte, en Grecia continental también tenemos la posible representación del barco solar en una crátera de tipo 282 de Tirinto del Heládico Final IIIc1 (Slenczka, 1974: 29-30,

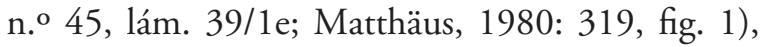
1185-1150 a. C., con el doble akroterion con posible cabeza de cisne por el cuello en 's' y la punta del pico hacia arriba (Fig. 10, n. ${ }^{\circ}$ 6). El sol no aparece con un círculo central completo, sino como tres semicírculos centrales, pero podrían representar el sol naciente o la puesta del sol. Como ya se ha señalado para el ámbito nórdico (Kaul, 1998: 245), patos y cisnes tienen una capacidad de moverse en los tres elementos, el celeste volando, el acuático flotando, $y$, finalmente, el subacuático, introduciéndose bajo el agua, en este último caso más claro en los patos que los cisnes que suelen introducir el cuello.

Durante el Hierro merece citarse para Grecia la tumba geométrica de la coraza de Argos, del Geométrico Reciente 2, donde junto a 12 obeloi de hierro aparecieron dos grandes morillos o chenets, uno de $1,29 \mathrm{~m}$ y otro de $1,34 \mathrm{~m}$, en forma de barco con cabezas de cisne hacia el interior en las dos posibles popas (Courbin, 1957: 336, 368-383, figs. 54-65). Esto implicaría que cuando estuvo encendido el fuego en la zona central entre los morillos simbolizaría la posición central del sol dentro del barco solar. Esta iconografía es mucho más frecuente en el ámbito de los Campos de Urnas, pero más como un elemento simbólico del barco solar que como barcos propiamente dichos, donde el elemento central es un sol y las cabezas de cisnes están en ambos extremos de estos barcos solares con pájaro, Vogel-Sonnenbarken, muchos de ellos representados en navajas del Bronce Nórdico (Sprockhoff, 1954: 41, figs. 6, 66; 18, 86 y 26a). Luego se incorporan en muchas sítulas de Hallstatt (Fig. 10.7) (Kossack, 1954: lám. 8; Sprockhoff, 1954: 45, fig. 8; Kastelic y Kromer, 1965; Matthäus, 1981; Wirth, 2006b: 553-561), o en la más recientemente vendida en Viena el año 2000, con forma similar a una de Hosszúpályi (Hajdú-Bihar, Hungría) (Wirth, 2006a: 336-337, fig. 6-8 y 2010: 5, figs. 4, 5 y 6), el mismo condado donde apareció otra sítula con similar iconografía en Hajdúböszörmény (Hajdú-Bihar), en el este de Hungría (Patai, 1990: lám. 30/57).

Otras áreas importantes en contacto con Centroeuropa fueron el Norte y Centro de Italia, donde la iconografía se considera llegada junto con el comercio del ámbar y alusiva de los contactos entre el Norte y el Sur de Europa, pues mostraría el descenso del sol en los confines noroccidentales del mundo (Verger, 2010: 297, fig. 2). En Italia se conocen 16 yacimientos con representaciones del barco solar en tumbas del Hierro i entre el 850-750 a. C., con un foco principal en Etruria, desde Volterra y Populonia hasta Tarquinia, Cerveteri o Veio, y una proyección puntual en Nápoles (Iasi, 2004: 309, 311-312, 316, fig. 1a). Las piezas más espectaculares quizás sean la sítula de la tumba AA1 (18) de Quattro Fontanili (Veio) y la de la tumba $\mathrm{M} 4$ de Arcatelle (Tarquinia) (Hencken, 1968: 183, figs. 169-170; Jockenhövel, 1974: 22, fig. 4; Iasi, 2004 :

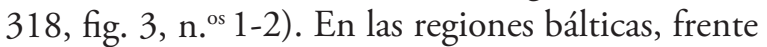
a los prótomos rectos de los barcos de los Pueblos del Mar, los barcos escandinavos presentan cuellos curvos más propios de cisnes y aparecen desde el Bronce III, 1325/1300-1100 a. C., de acuerdo con el cuerno de Wismar Mecklenburg, y se generalizan a partir del Bronce IV, 1100-950/900 a. C., Bronce v, 950/900-700 a. C., y Bronce vi, 700-500 a. C. (Kaul, 1998: 88, fig. 53). Solo en navajas de afeitar aparecen excepcionalmente aves representadas completas, con la punta del pico hacia abajo (Johansen y Johansen, 1983: 94, fig. 15a-e, 95, fig. 16a-b; Kaul, 1998: 243-244, fig. 164), interpretadas como aves de presa que se alimentaban de los peces (Johansen y Johansen, 1983; Kaul, 1998: 245), al contrario que los representados en los barcos solares con el pico hacia arriba, pero que nosotros creemos que podrían corresponder a pájaros utilizados durante la navegación para detectar la proximidad a la costa, caso de los córvidos. En el ámbito del Bronce Nórdico y Centroeuropeo fue a partir del Bronce IV cuando se generalizaron los barcos solares, siendo 
un excelente ejemplo la decoración de la sítula de bronce de Mariesminde Mose (Funen, Dinamarca), localizada en 1862, que contenía 11 cuencos de oro en su interior (Worsaae, 1882; Thrane, 1965: fig. 20a-b), muy parecida a la sítula de la tumba de Gevelinghausen, Meschede (Sauerland), en el norte de Alemania (Jockenhövel, 1974: 20-21, fig. 2-3, lám. 1-3), aunque en este caso presenta también un pie como las sítulas etruscas. En general, en la interpretación de la mitología nórdica durante el Bronce Final, sobre todo a partir del Bronce III, desde el 1300 a. C., el sol tendría un ciclo solar parecido al egipcio (Sprockhoff, 1955: 108-109). La divinidad solar se movería durante el día en un carro solar tirado por caballos, y en cambio durante la noche sería transportado por un barco con proa y popa con cabezas de cisne, proponiéndose que tendrían especial importancia durante el amanecer y la puesta del sol, al poder volar los cisnes por el día y nadar por la noche (Gelling y Davidson, 1969: 49, 119; Kaul, 1998: 245, 261-262, fig. 179; Kristiansen y Larsson, 2006: 340-341, fig. 139).

Ya en ámbito mediterráneo, debe tenerse en cuenta que la diosa 's $s r t$ era patrona de los marinos y de las exploraciones, como Atenea, y como estrella de Venus, al igual que Ishtar, servía de guía a los marinos como la primera estrella vespertina que se ve hacia el oeste en la noche durante tres horas, lucero de la tarde o nocturnus, pues es el elemento celeste más brillante después del sol y la luna, y se mantiene al amanecer hacia el Este, siendo denominada "lucero del alba". Las estrellas eran los principales referentes durante la navegación nocturna, pues Odiseo “... velaba a las Pléyades vuelto, al Boyero de ocaso tardío y a la Osa, que otros dan nombre del Carro y que gira sin dejar su lugar al acecho de Orión" (Hom., Od., v, 271-274). Sellos levantinos de Sidón, Dor y otras ciudades representan a Astarté-Ishtar asociada con las Pléyades (Keel y Uehlinger, 1992/1998: 292-293, fig. 286-288; Stager, 1995: 440). Esta vinculación con la navegación es muy clara en Astarté Shemayim - celeste- o Afrodita Urania, Ov̉pavía, -celestial-, cuyo santuario más antiguo se encontraba en Ashkelon en Palestina, “... el más antiguo de todos los santuarios consagrados a esa diosa, pues incluso el de Chipre, al decir de los chipriotas, tuvo en él su origen y fueron unos fenicios...” (Hrdt., I, 105, 2-3; Paus., I, 14, 7). Las palomas u otras aves eran importantes en la navegación para conocer la proximidad de la costa desde las embarcaciones (Luzón y Coín, 1986), siendo un buen ejemplo cómo eran utilizadas en la navegación en el océano Índico hacia Ceilán, denominada Trapóbane, “... Llevan consigo pájaros que sueltan muy a menudo, y acompañan su vuelo cuando se dirigen a tierra..." (Plin., N.H., vi, 83).

Finalmente, cabe destacar la vinculación con la realeza de estas divinidades. Los reyes de Sidón eran sacerdotes de ‘̌s $s$, como señala la inscripción KAI 13 (Donner y Röllig, 1978) en el sarcófago del rey de Sidón, Tabnit, de inicios del s. v a. C. “... Yo, Tabnit, sacerdote de Astarté, rey de Sidón, el hijo de $E s-$ hmunazar, sacerdote de Astarté, rey de Sidón, estoy reposando en este sarcófago...”. Por su parte, $\mathrm{Ha}$ thor era madre protectora de los faraones egipcios desde el Imperio Antiguo y las reinas de Egipto desde finales de la Dinastía XVIII, durante el Imperio Nuevo, también empezaron a representarse con el peinado de Hathor. Por ello, esta divinidad $q d s^{2}-{ }^{\prime} s r t$ puede también estar simbolizando la realeza, uno de cuyos miembros pudo ser el enterrado en la tumba o las tumbas de la cual, probablemente, procederían los tres bocados de caballo.

\section{Conclusiones}

Los dos bronces figurativos conservados desde 1999 en el Metropolitan Museum de New York que aquí hemos estudiado pueden identificarse como dos camas laterales de un mismo bocado de caballo producido durante el Periodo Orientalizante -s. vII a. C.- en un taller de broncistas fenicios asentado en la Península Ibérica. El análisis de la documentación conservada en el museo, así como su estudio técnico y formal, apuntan unívocamente en esta dirección, en contra de afirmaciones anteriores que, incluso, han llegado a cuestionar la autenticidad -entendida esta como antigüedad- de las piezas. Su similitud con el célebre Bronce Carriazo permite considerar a este grupo dentro de los estándares de la broncística hispano-fenicia de la 
que constituyen piezas sobresalientes, tanto en lo estético como en lo iconográfico, lo que justifica el carácter emblemático que han alcanzado. En estos herrajes se supedita la funcionalidad del objeto a su valor decorativo, constituyendo algunos de los escasos exponentes antiguos donde las camas de los frenos no se perforan para pasar los filetes, sino que se dotan de agarres fijos a los que se sujetan cañones y riendas. De este modo no se interfiere en las vistosas decoraciones que representan. Sin embargo, las soluciones técnicas arbitradas para articular los dos conjuntos conocidos fueron diferentes: una anilla vertical en el Bronce Carriazo y una anilla doble en el par del MMA. Otros bocados hispánicos, como el ya referido del FARMM, inciden en esta característica de camas no perforadas. A pesar de la gran similitud formal que vincula a estos nuevos bronces con la ya conocida pieza sevillana, debemos convenir en que se trata de objetos muy diferenciados, que se trabajaban de manera individual, aunque, como demuestra esta coincidencia, a veces se siguieran modelos similares. El doble sistema de sujeción empleado por el Bronce Carriazo y por las placas del mMA sugiere, a este respecto, una escasa seriación en las producciones. La mayoría de los pocos bocados orientalizantes conocidos hasta la fecha destacan por su gran polimorfismo y, aunque se mantienen componentes esenciales en la estructura de algunos ejemplares -como su disposición horizontal, el doble agarre superior y las perforaciones inferiores-, siguen apareciendo unidades que renuevan la tipología y aumentan la variedad, como el ejemplar de la comarca de La Serena que hemos referido aquí, y que presenta unas decorativas camas discoidales profusamente caladas con motivos fenicios.

La divinidad del Bronce Carriazo y de los dos bocados del Metropolitan creemos que corresponde a la diosa qudšu 'aštart, aunque también ha sido considerada la diosa Hathor hwt-hr por el uso del peinado hathórico. Se trata de una diosa guerrera, lo que explica su presencia en estos bocados de caballos que también podrían ser parte del tiro de un carro, como "Astarté, señora de los caballos, la Dama del carro" -KAI 13-. Por otra parte, pueden sugerir una vinculación con la realeza pues los reyes de Sidón eran sacerdotes de 'šrt. Los dos ánades que levantan vuelo pueden entenderse como propios de una divinidad alada que remonta el vuelo con ellas, que también lo era " $\stackrel{s}{r} r$, 'Reina de los Cielos" (Jr, 7, 18). La roseta de 16 pétalos presente en el pecho de la diosa evoca el disco solar. Estas dos cabezas de ánades a ambos extremos parecen formar la proa y la popa una barca solar con dos prótomos de aves, ya que el recorrido del sol tiene su amanecer o aurora en Oriente y su puesta u ocaso en Occidente. El barco solar navegaría por un cielo de agua y simbolizaba el viaje al más allá, al extremo Occidente. Los barcos con proa y popa con cabeza de ánade aparecen con los Pueblos del Mar, Prst Peleset, Tkr Tjekker y $\breve{S} r d n$ Sherden, desde inicios del s. XII a. C. Por otra parte, la diosa 'šr era patrona de los marinos y de las exploraciones como estrella de Venus, sirviendo de guía a los marinos como la primera estrella vespertina, lucero de la tarde, y reaparecía al amanecer, lucero del alba.

Es necesario señalar, por último, que el reconocimiento de estos nuevos atalajes, profusamente decorados, obliga a reconsiderar al alza el papel del elemento ecuestre entre los componentes que definen y representan a las aristocracias orientalizantes ibéricas. Aunque, desgraciadamente, estas evidencias carecen de contexto arqueológico que permita precisar si son objetos de monta o si pertenecen a un carruaje, su sola presencia en un panorama caracterizado por la extrema escasez (Jiménez Ávila, 2002; Quesada, 2005), así como las novedades que se derivan de su estudio, resultan ya de por sí apreciables aportaciones.

\section{Fuentes antiguas}

Ateneo (2006): Banquete de los eruditos. Libros VIII-X. Trad. Rodríguez-Noriega, L. Biblioteca Clásica Gredos, 350. Madrid: Gredos.

Herodoto (1977): Historia. Libros I-II. Trad. de SchraDER, C. Madrid: Biblioteca Clásica Gredos, 3. Gredos.

Higinio, C. J. (2009): Fábulas. Trad. de Del Hoyo, J. y García Ruiz, J. M. Madrid: Biblioteca Clásica Gredos, 380. Gredos.

Homero (1982): Odisea. Trad. de Pabón, J. M. Madrid: Biblioteca Clásica Gredos, 48. Gredos. 
Pausanias (1994): Descripción de Grecia. Libros I-II. Trad. Herrero, M. ${ }^{a}$ C. Biblioteca Clásica Gredos, 196. Madrid.

Plinio el Viejo (1998): Historia Natural. Libros III-VI. Trad. Fontán, A. (Libro III), García Arribas, I. (Libro IV); Del Barrio, E. (Libro v) y Arribas, M. ${ }^{\text {a L. }}$ (Libro vi). Biblioteca Clásica Gredos, 250. Madrid.

\section{Bibliografía}

Albright, W. F. (1942): Archaeology and the Religion of Israel. Baltimore-London: The Johns Hopkins PressOUP.

Albright, W. F. (1968): Yahweh and the Gods of Canaan: An Historical Analysis of Two Contrasting Faiths. The Jordan Lectures 1965. New York: Doubleday.

Almagro Basch, M. (1979): "Los orígenes de la toréutica ibérica”, Trabajos de Prehistoria, 36, pp. 173-211.

Almagro-Gorbea, M. (1977): El Bronce Final y el Periodo Orientalizante en Extremadura. Bibliotheca Praehistorica Hispana, 14. Madrid: csic.

Almagro-Gorbea, M. (1978): "Pozo Moro y la formación de la cultura ibérica”, Saguntum, 13, pp. 227246.

Almagro-Gorbea, M. (1996): Ideología y Poder en Tartessos y el mundo ibérico. Madrid: RAH.

Almagro-Gorbea, M. (2004): "Iconografía fenicia y mitología tartésica. El influjo fenicio en las creencias de Tartessos". En Acquaro, E. y Savio, G. (eds.): Studi iconografici nel Mediterraneo antico: iconologia ed aspetti materici. Studi e ricerche sul beni culturali, 6. Sarzana: Agorà, pp. 11-64.

Almagro-Gorbea, M. (2008): "Objetos de marfil y hueso". En Almagro Gorbea, M.; Lorrio, A. J.; Mederos, A. y Torres, M. (eds.): La necrópolis de Medellín. II. Estudio de los hallazgos. Bibliotheca Archaeologica Hispana, 26 (2). Studia Hispano-Phoenicia, 5 (2). Madrid: RAH, pp. 401-512.

Blanco Freijeiro, A. (1960): "Notas de Arqueología andaluza”, Zephyrus, 11, pp. 151-163.

Blanco Freijeiro, A. (1981): Historia del Arte Hispánico I.2. La Antigüedad. Madrid: Alhambra.

Blánquez PÉrez, J. (1999): "El tratamiento informático y los vestigios ibéricos. Algunos ejemplos”. En Blánquez, J. y Roldán, L. (eds.): La Cultura Ibérica a través de la fotografia de principios de siglo. Un homenaje a la memoria. Madrid: UAM, pp. 265-270.
Blázquez Martínez, J. M. ${ }^{a}$ (1975): Tartessos y los origenes de la colonización fenicia en Occidente (2a ed.). Salamanca: Univ. de Salamanca.

Blázquez Martínez, J. M.a (1983): Primitivas religiones ibéricas. II. Religiones prerromanas. Madrid: Cristiandad.

Blech, M. (2003): "Elementos de atalaje de Cancho Roano”. En Celestino, S. (ed.): Cancho Roano IX. Los materiales arqueológicos II. Badajoz: Bartolomé Gil Santacruz, pp. 159-192.

Bleeker, C. J. (1973): Hathor and Thoth: Two Key Figures of the Ancient Egyptian Religion. Leiden: Brill.

Bonnet, C. (1988): Melqart: cultes et mythes de l'Héraclès tyrien en Méditerranée. Bibliothèque de la Faculté de Philosophie et Lettres de Namur, 69. Studia Phoenicia, 8. Leuven: Uitgeverij Peeters.

Bonnet, C. (1996): Astarté. Dossier documentaire et perspectives historiques. Contributi alla Storia della Religione Fenicio-Punica, 2. Collezione di Studi Fenici, 37. Istituto per la Civiltà Fenicia e Punica. Roma: Consiglio Nazionale delle Ricerche.

Boreux, C. (1939): "La stèle C.86 du Musée du Louvre et les stèles similaires". Mélanges Syriens offerts a Monsieur René Dussaud par ses amis et ses élèves. II. Bibliothèque Archéologique et Historique, 30. Paris: Librairie Orientaliste Paul Geuthner, pp. 673-687.

Bosch Gimpera, P. (1975): Prehistoria de Europa. Madrid: Istmo.

Bouzer, J. (1985): The Aegean, Anatolia and Europe: Cultural Interrelations in the Second Millennium B.C. Studies in Mediterranean Archaeology, 29. Göteborg: Paul Aströms Förlag-Czechoslovak Academy of Sciences.

Carriazo y Arroquia, J. de M. (1973): Tartessos y El Carambolo. Investigaciones arqueológicas sobre la Protohistoria de la Baja Andalucía. Arte de España, 4. Madrid: Ministerio de Educación y Ciencia.

Carriazo y Arroquia, J. de M. ([1980] 1974): Protohistoria de Sevilla. En el vértice de Tartessos. Sevilla: Ediciones Guadalquivir.

Coldstream, J. N. (1984): “A Protogeometric Nature Goddess from Knossos", Bulletin of the Institute of Classical Studies, 31, pp. 93-104.

Corzo, R. (2007): “Dos copias del 'Bronce Carriazo' en el Museo Metropolitano de New York”, Temas de Historia y Arte, 21, pp. 35-47.

Courbin, P. (1957): "Une tombe géométrique d'Argos", Bulletin de Correspondance Hellénique, 81, pp. 322-386; https://doi.org/10.3406/bch.1957.2376 
Cross, F. M. (1973): Canaanite Myth and Hebrew Epic. Essays in the History of the Religion of Israel. Cambridge, Mass.: Hup.

DAthe, H. y Krüger, H. (2018): "Morphometric findings on the Nebra Sky Disc", Time and Mind, 11 (1): 89-104. https://doi.org/10.1080/1751696X.2018.1433358

Donner, H. y RölLig, W. (1978-80): Kanaanäische und aramäische Inschriften. I-III. KAI, 4. ${ }^{\mathrm{a}}$ ed. Wiesbaden: Otto Harrassowitz.

Edwards, I. E. S. (1955): "A Relief of Qudshu-Astarte-Anath in the Winchester College Collection", Journal of Near Eastern Studies, 14 (1), pp. 49-51. https://doi.org/10.1086/371241

EsCACENA, J. L. (2011-12): "El firmamento en un cuenco de cerámica. Viaje a las ideas calcolíticas sobre la bóveda celeste". Homenaje a M. Bendala, Cuadernos de Prehistoria y Arqueología de la Univ. Autónoma de Madrid, 37-38 (1), pp. 153-194. https://doi. org/10.15366/cupauam2012.38.008

Escacena, J. L. (2015): "Cielos fosilizados", Quaderns de Prehistòria i Arqueologia de Castelló, 33, pp. 43-61.

Fulco, W. J. (1976): The Canaanite God Rešep. New Haven: American Oriental Society.

Garcia y Bellido, A. (1969): "Los Bronces tartésicos". En Tartessos y sus problemas. $V$ Symposium Internacional de Prehistoria Peninsular (Jerez, 1968). Publicaciones Eventuales, 13. Barcelona: Univ. de Barcelona, pp. 163-171.

Gelling, P. y Davidson, H. E. (1969): The Chariots of the Sun, and other rites and symbols of the Northern Bronze Age. New York: Frederick A. Praeger.

Gjerstad, E. (1944): "The Colonization of Cyprus in Greek Legend", Opuscula Archaeologica, 3, pp. 107-123.

Goedike, H. (1970): The Report about the Dispute of a Man with his Ba. Baltimore-London: Johns Hopkins Press.

Hencken, H. (1968): Tarquinia. Villanovans and Early Etruscans. Bulletin of the American School of Prehistoric Research, 23. Cambridge, Mass.: Peabody Museum.

IAIA, C. (2004): "Lo stile della "barca solare ornitomorfa' nella toreutica italiana della Prima Età del Ferro". En Cattacchio, N. (ed.): Preistoria e Protostoria in Etruria: miti, simboli, decorazioni, ricerche e scavi. VI Incontro di Studi Preistoria e Protostoria in Etruria (Pitigliano, Valentano, 2002). Milano: Centro di Studi di Preistoria e Archeologia, pp. 307-318.
JimÉNez Ávila, J. (2002): La Toréutica Orientalizante en la Península Ibérica. Bibliotheca Archaeologica Hispana, 16. Madrid: RAH.

Jiménez Ávila, J. (2015): "Phoenician Bronzes in Spain. A Western Phoenician Bronzework". En JimÉNEZ Ávila, J. (ed.): Phoenician Bronzes in Mediterranean. Bibliotheca Archaeologica Hispana, 45. Madrid: RAH, pp. 395-441.

Jiménez Ávila, J. (2018a): “Un conjunto de arreos de bronce de la Colección Juan Cabré: Aportaciones al estudio del atalaje ecuestre en la Protohistoria Ibérica”, Espacio, Tiempo y Forma. Serie I. Prehistoria y Arqueología, 11, pp. 49-73.

Jiménez Ávila, J. (2018b): "Timiaterio Fenicio Occidental”. En Almagro-Gorbea, M. (ed.): Joyas de la Arqueología Española: Colección Cervera. Barcelona: Félix Cervera Correa, pp. 127-159.

JimÉnez Ávila, J. (2020): "Voces de muerte sonaron lejos del Guadalquivir: El mundo funerario del Guadiana medio en época orientalizante". En AlbuQuerque, P.; Sáez, A. y García Fernández, F. J. (eds.): Eternidades compartidas. El mundo funerario a occidente de las Columnas de Melqart. Sevilla.

Jockenhövel, A. (1974): "Eine Bronzeamphore des 8. Jahrhunderts v. Chr. von Gevelinghausen, Kr. Meschede (Sauerland)", Germania, 52: 16-54.

Johansen, E. y Johansen, Ø. (1983): "Bronsefunnene fra Vansjø”, Viking, 47, pp. 66-106.

Kastelic, J. y Kromer, K. (1965): Situla Art: Ceremonial Bronzes of Ancient Europe. New York: McGraw-Hill.

Kaul, F. (1998): Ships on Bronzes. A Study in Bronze Age Religion and Iconography. Studies in Archaeology and History, 3 (1-2). Copenhagen: The National Museum of Denmark.

Keel, O. y Uehlinger, C. (1992): Göttinnen, Götter und Gottessymbole. Neue erkenntnisse zur religionsgeschichte Kanaans und Israels. Aufgrund bislang unerschlossener ikonographischer quellen. Freiburg: Quaestiones Disputatae, 134. Herder.

Keel, O. y Uehlinger, C. ([1998] 1992): Gods, Goddesses, and Images of God in Ancient Israel. Minneapolis: Augsburg Fortress Press.

Kossack, G. (1954): Studien zum Symbolgut der Urnenfelder-und Hallstattzeit Mitteleuropas. Band 20. Berlín: Romisch Germanische Forschungen.

Kristiansen, K. (1998): Europe Before History. Cambridge: cup.

Kristiansen, K. y Larsson, T. B. (2006): La emergencia de la sociedad del Bronce. Viajes, transmisiones y transformaciones. Barcelona: Bellaterra. 
Landström, B. (1961): Skeppet. Stockholm: Bokförlaget Forum AB.

LeClant, J. (1960): "Astarté à cheval d'après les représentations égyptiennes”, Syria, 37, pp. 1-67.

Lipinski, E. (1972): "The Goddess Atirat in Ancient Arabia, in Babylon, and in Ugarit", Orientalia Lovaniensia Periodica, 3, pp. 101-119.

Lipinski, E. (1986): “The Syro-Palestinian Iconography of Woman and Goddess", Israel Exploration Journal, 36 (1-2), pp. 87-96.

Lipinski, E. (1995): Dieux et déesses de l'univers phénicien et punique. Orientalia Lovaniensia Analecta, 64. Studia Phoenicia, 14. Leuven: Uitgeverij Peeters \& Departement Oosterse Studies.

Littauer, M. y Crouwel, J. H. (1979): Wheeled Vehicles and Ridden Animals in the Ancient Near East. Handbuch der Orientalistik, 7. Leiden-Köln: Brill.

López Grande, M.a J. (1998): "Imágenes de la diosa $q d{ }^{2}$ en la documentación egipcia", Cuadernos de Prehistoria y Arqueología de la Universidad Autónoma de Madrid, 25, pp. 135-155. https://doi.org/10.15366/ cupauam 1999.25.1.006

López Grande, M.a J. y Trello, J. (2004): "Pervivencias iconográficas egipcias en las imágenes de damas sagradas del ámbito Fenicio-Púnico". En González Blanco, A.; Matilla, G. y Egea, A. (eds.): El mundo púnico. Religión, antropología y cultura material. II Congreso Internacional del Mundo Púnico (Cartagena, 2000). Estudios Orientales, 5-6. Murcia: Univ. de Murcia, pp. 337-352.

López PARDO, F. (2006): La torre de las almas. Un recorrido por los mitos y creencias del mundo fenicio y orientalizante a través del monumento de Pozo Moro. Gerión, Anejo 10. Madrid: Univ. Complutense de Madrid.

Luzón, J. M. a y Coin, L. M. (1986): "La navegación pre-astronómica en la Antigüedad: utilización de pájaros en la orientación náutica", Lucentum, 5, pp. 65-85. https://doi.org/10.14198/LVCENTVM1986.5.04

Maier, W. A. (1986): 'Ašserah. Extrabiblical Evidence. Harvard Semitic Monographs, 37. Atlanta: Scholars Press.

Maluquer de Motes, J. (1957): "De metalurgia tartesia: el bronce Carriazo”, Zephyrus, viII, pp. 157-168.

Maluquer de Motes, J. ([1989] 1968): Tartessos. La ciudad sin historia. Barcelona: Destino.

Maraszer, R. (2010): "Ein Schiff auf dem Himmelsozean-Zur Deutung des gefiederten Goldbogens auf der Himmelsscheibe von Nebra". En Meller, H. y Bertemes. F. (eds.): Der Griff nach den Sternen: wie
Europas Eliten zu Macht und Reichtum kamen (Halle, Saale, 2005). Tagungen des Landesmuseums für Vorgeschichte Halle, 5 (1-2). Halle: Landesamt für Denkmalpflege und Archäologie in SachsenAnhalt, pp. 487-500.

Marín, M. a C. y Ferrer, E. (2011): "El Bronce Carriazo. Historia y lectura iconográfica de una pieza singular". En Belmonte, J. A. y Oliva, J. C. (eds.): Esta Toledo, aquella Babilonia: convivencia e interacción en las sociedades del Oriente y del Mediterráneo antiguo. $\checkmark$ Congreso Español del Centro de Estudios del Próximo Oriente (Toledo, 2009). Colección Studios, 111. Toledo: Univ. de Castilla-La Mancha, pp. 615-645.

MatтнӓUs, H. (1980): "Mykenische Vogelbarken. Antithetische Tierprotomen in der Kunst des östlichen Mittelmeerraumes", Archäologisches Korrespondenzblatt, 10, pp. 319-330.

MAтTHäUs, H. (1981): "KYKNOI $\triangle \mathrm{E} H \Sigma A N$ TO APMA. Spätmykenische und urnenfelderzeitliche Vogelplastik". En Lorenz, H. (ed.): Studien zur Bronzezeit. Festchrift für Wilhelm Albert von Brunn. Mainz: Philipp von Zabern, pp. 277-299.

Meller, H. (2002): "Die Himmelsscheibe von Nebra-ein frühbronzezeitlicher Fund von aussergewöhnlicher Bedeutung", Archäologie in Sachsen-Anhalt, 1, pp. 7-20.

Meller, H. (2004): "Die Himmelsscheibe von Nebra". En Meller, H. (ed.): Der geschmiedete Himmel. Die weite Welt im Herzen Europas vor 3600 Jahren (Halle, Saale, 2004-05). Stuttgart: Landesmuseums für Vorgeschichte-Konrad Theiss, pp. 22-31.

Meller, H. (2010): "Nebra: Vom Logos zum Mythos-Biographie eines Himmelsbildes". En Meller, H. y Bertemes, F. (eds.): Der Griff nach den Sternen: wie Europas Eliten zu Macht und Reichtum kamen (Halle, Saale, 2005). Tagungen des Landesmuseums für Vorgeschichte Halle, 5 (1-2). Halle: Landesamt für Denkmalpflege und Archäologie in Sachsen-Anhalt, pp. 23-73.

Nelson, H. H. (1930): Medinet Habu Reports. I. Earlier Historical Records of Ramses III: Plates 1-54. Oriental Institute Publications, 10. Chicago: University of Chicago Press.

Olmos, R.; Tortosa, T. e Iguácel, P. (1992): "Catálogo”. En Olmos, R. (ed.): La sociedad ibérica a través de la imagen. Catálogo de exposición (Albacete-Murcia-Valencia-Alicante-Badajoz, 1992-93). Madrid: Ministerio de Cultura, pp. 33-182. 
PÁsztor, E. y Roslund, C. (2007): “An interpretation of the Nebra disc", Antiquity, 81 (312), pp. 267-278. https://doi.org/10.1017/S0003598X00095168

Patay, P. (1990): Die Bronzegefäße in Ungarn. Prähistorische Bronzefunde, II 10. München: Beck.

Pritchard, J. B. (1943): Palestinian Figurines in relation to certain Goddesses Known through Literature. American Oriental Series, 24. New Haven: American Oriental Society.

Puech, E. (1976): "Le rite d'offrande de cheveux d'après une inscription phénicienne de Kition vers 800 avant notre ère", Rivista di Studi Fenici, 4 (1), pp. 11-21.

Quesada, F. (2005): "El gobierno del caballo montado en la antigüedad clásica con especial referencia al caso de Iberia. Bocados, espuelas y la cuestión de la silla de montar, estribos y herraduras", Gladius, 25, pp. $97-$ 150. https://doi.org/10.3989/gladius.2005.26

Ruiz Mata, D. (1994): “Tartessos”. En Domínguez Ortiz, A. (ed.): Historia de España. I. Desde la prehistoria hasta la conquista romana (siglo III a. C.). Barcelona: Planeta, pp. 378-429.

Schlosser, W. (2002): "Zur astronomischen Deutung der Himmelsscheibe von Nebra”, Archaologie in Sachsen-Anhalt, 1, pp. 21-23.

Schlosser, W. (2004): "El disco de Nebra, ¿un calendario agrícola?”, Investigación y Ciencia, 335, pp. 76-84.

Schlosser, W. (2010): "Die Himmelsscheibe von Nebra-Astronomische Untersuchungen”. En Meller, H. y Bertemes, F. (eds.): Der Griff nach den Sternen: wie Europas Eliten zu Macht und Reichtum kamen (Halle, Saale, 2005). Tagungen des Landesmuseums für Vorgeschichte Halle, 5 (1-2). Halle: Landesamt für Denkmalpflege und Archäologie in Sachsen-Anhalt, pp. 913-933.

SlenczKa, E. (1974): Tiryns VII. Figürlich bemalte mykenische Keramik aus Tiryns. Tiryns, Forschungen und Berichte, 8. Mainz am Rhein: Phillip von Zabern.

Sprockнoff, E. (1954): "Nordische Bronzezeit und frühes griechentum", Jahrbuch des Römish-Germanischen Zentralmuseums, 1, pp. 28-110.

Sprockнoff, E. (1955): "Das bronzene Zierband von Kronshagen bei Kiel. Eine Ornamentstudie zur Vorgeschichte der Vogelsonnen barke", Offa, 14, pp. 5-120.

Stager, J. M. S. (2005): "Let no one wonder at this image'. A Phoenician Funerary Stele in Athens”, Hesperia, 74, pp. 427-449.

Tazawa, K. (2014): "Astarte in New Kingdom Egypt: Reconsideration of Her Role and Function". En Sugiмото, D. T. (ed.): Transformations of a Goddess:
Ishtar-Astarte-Aphrodite. Fribourg-Göttingen: Academic Press-Vandenhoeck Ruprecht, pp. 103-124.

Thrane, H. (1965): "Dänische Funde fremder Bronzegefäße der jüngeren Bronzezeit (Periode IV)", Acta Archaeologica, 36, pp. 157-207.

Torres Ortiz, M. (2002): Tartessos. Bibliotheca Archaeologica Hispana, 14. Madrid: RAH.

Ubieta, J. A. (ed.) (1994): Biblia de Jerusalén. Madrid-Bilbao: Alianza Editorial-Desclée de Brouwer.

Verger, S. (2010): “Archéologie du couchant d'été”. En Le Bihan, J.-P. y Guillaumet, J.-P. (eds.): Routes du monde et passages obligés: de la protohistoire au haut Moyen-Age (Ouessant, 2007). Quimper: Centre de Recherche Archéologique du Finistère, pp. 293-337.

Vermeule, E. y Karageorghis, V. (1982): Mycenaean Pictorial Vase Painting. Cambridge-London: Hup.

Wachsmann, S. (1981): "The ships of the Sea Peoples", The International Journal of Nautical Archaeology and Underwater Exploration, 10 (3), pp. 187-220. https://doi.org/10.1111/j.1095-9270.1981.tb00030.x

Winter, U. (1983): Frau und Göttin. Exegetische und Ikonographische Studien zum weiblichen Gottesbild im Alten Israel und in dessen Umwelt. Orbis Biblicus et Orientalis, 53. Göttingen: Universitätverlag Freiburg-Vanderhoeck \& Ruprecht.

Wirth, S. (2006a): "Le mystère de la barque solaire: quelques considérations à propos des décors sur les situles du type Hajdúböszörmény et sur une situle inédite du Bronze final". En Baray, L. (ed.): Artisanats, sociétés et civilisations: hommage à Jean-Paul Thevenot. Revue Archéologique de l'Est, Suppl. 24. Dijon, pp. 331-345.

Wirth, S. (2006b): "Vogel-sonnen-barke". En H. BeCK; Geuenich, D. y Steuer, H. (eds.): Reallexikon der Germanischen Altertumskunde, 32. Berlin-New York: De Gruyter, pp. 552-563.

Wirth, S. (2010): "Sonnenbarke und zyklisches Weltbild-Überlegungen zum Verständnis der spätbronzezeitlichen Ikonographie in Mitteleuropa". En MELler, H. y Bertemes, F. (eds.): Der Griff nach den Sternen: wie Europas Eliten zu Macht und Reichtum kamen (Halle, Saale, 2005). Tagungen des Landesmuseums für Vorgeschichte Halle, 5 (1-2). Halle: Landesamt für Denkmalpflege und Archäologie in Sachsen-Anhalt, pp. 501-515.

Worsane, J. J. A. (1882): The Industrial Arts of Denmark, from the earliest times to the Danish conquest of England. London: South Kensington Museum Art Handbooks. 